Atmos. Chem. Phys., 13, 10951-10967, 2013

www.atmos-chem-phys.net/13/10951/2013/

doi:10.5194/acp-13-10951-2013

(c) Author(s) 2013. CC Attribution 3.0 License.

\title{
Forcing of stratospheric chemistry and dynamics during the Dalton Minimum
}

\author{
J. G. Anet ${ }^{1}$, S. Muthers ${ }^{2,3}$, E. Rozanov ${ }^{1,4}$, C. C. Raible ${ }^{2,3}$, T. Peter ${ }^{1}$, A. Stenke ${ }^{1}$, A. I. Shapiro ${ }^{4}$, J. Beer ${ }^{5}$, \\ F. Steinhilber ${ }^{5}$, S. Brönnimann ${ }^{3,6}$, F. Arfeuille ${ }^{3,6}$, Y. Brugnara ${ }^{3,6}$, and W. Schmutz ${ }^{4}$ \\ ${ }^{1}$ Institute for Atmospheric and Climate Science ETH, Zurich, Switzerland \\ ${ }^{2}$ Climate and Environment Physics, Physics Institute, University of Bern, Bern, Switzerland \\ ${ }^{3}$ Oeschger Centre for Climate Change Research, University of Bern, Bern, Switzerland \\ ${ }^{4}$ Physikalisch-Meteorologisches Observatorium Davos and World Radiation Center (PMOD/WRC), Davos, Switzerland \\ ${ }^{5}$ Eawag, Surface Waters Group, Kastanienbaum, Switzerland \\ ${ }^{6}$ Institute of Geography, University of Bern, Bern, Switzerland
}

Correspondence to: J. G. Anet (julien.anet@alumni.ethz.ch)

Received: 16 April 2013 - Published in Atmos. Chem. Phys. Discuss.: 10 June 2013

Revised: 11 October 2013 - Accepted: 11 October 2013 - Published: 8 November 2013

\begin{abstract}
The response of atmospheric chemistry and dynamics to volcanic eruptions and to a decrease in solar activity during the Dalton Minimum is investigated with the fully coupled atmosphere-ocean chemistry general circulation model SOCOL-MPIOM (modeling tools for studies of SOlar Climate Ozone Links-Max Planck Institute Ocean Model) covering the time period 1780 to $1840 \mathrm{AD}$. We carried out several sensitivity ensemble experiments to separate the effects of (i) reduced solar ultra-violet (UV) irradiance, (ii) reduced solar visible and near infrared irradiance, (iii) enhanced galactic cosmic ray intensity as well as less intensive solar energetic proton events and auroral electron precipitation, and (iv) volcanic aerosols. The introduced changes of UV irradiance and volcanic aerosols significantly influence stratospheric dynamics in the early 19th century, whereas changes in the visible part of the spectrum and energetic particles have smaller effects. A reduction of UV irradiance by $15 \%$, which represents the presently discussed highest estimate of UV irradiance change caused by solar activity changes, causes global ozone decrease below the stratopause reaching as much as $8 \%$ in the midlatitudes at $5 \mathrm{hPa}$ and a significant stratospheric cooling of up to $2{ }^{\circ} \mathrm{C}$ in the midstratosphere and to $6^{\circ} \mathrm{C}$ in the lower mesosphere. Changes in energetic particle precipitation lead only to minor changes in the yearly averaged temperature fields in the stratosphere. Volcanic aerosols heat the tropical lower stratosphere, allowing more water vapour to enter the tropical stratosphere,
\end{abstract}

which, via $\mathrm{HO}_{\mathrm{x}}$ reactions, decreases upper stratospheric and mesospheric ozone by roughly $4 \%$. Conversely, heterogeneous chemistry on aerosols reduces stratospheric $\mathrm{NO}_{\mathrm{x}}$, leading to a $12 \%$ ozone increase in the tropics, whereas a decrease in ozone of up to $5 \%$ is found over Antarctica in boreal winter. The linear superposition of the different contributions is not equivalent to the response obtained in a simulation when all forcing factors are applied during the Dalton Minimum (DM) - this effect is especially well visible for $\mathrm{NO}_{\mathrm{x}} / \mathrm{NO}_{\mathrm{y}}$. Thus, this study also shows the non-linear behaviour of the coupled chemistry-climate system. Finally, we conclude that especially UV and volcanic eruptions dominate the changes in the ozone, temperature and dynamics while the $\mathrm{NO}_{\mathrm{x}}$ field is dominated by the energetic particle precipitation. Visible radiation changes have only very minor effects on both stratospheric dynamics and chemistry.

\section{Introduction}

The fourth assessment report of the Intergovernmental Panel on Climate Change (Forster et al., 2007) noted that while the scientific understanding of the greenhouse gas (GHG) emissions and volcanic effects on climate is rather high, this is not the case for changes in solar activity. The combined forcings of GHG and tropospheric aerosols is predicted to increase until possible stabilization is reached in the second 
half of the 21st century. The volcanic effect is unpredictable. Concerning solar activity, it is hypothesized that solar activity will - after a long period of high activity - drop to a new grand minimum in the 21st century (Abreu et al., 2008, 2010; Lockwood et al., 2011b; Steinhilber and Beer, 2013). Given this, an assessment of periods in the past containing grand solar minima is helpful to understand the mechanism and its implications. As an example, the Dalton Minimum (DM) was a time period lasting from 1790 to 1830 which was characterized by a significant cooling in Europe (Luterbacher et al., 2004) and the extratropical Northern Hemisphere (Ljungqvist, 2010; Auchmann et al., 2012). This unusually cold time coincides with the period of very low solar activity as expressed in low sunspot numbers (Hoyt and Schatten, 1998) and high volcanic activity due to two major volcanic eruptions in 1809 and in 1815 . The exact causes of this cooling are not well defined. Some part of it can be explained by downward-propagating stratospheric perturbations (e.g. Ineson et al., 2011). We thus decided to study this period and address the solar and volcanic effects on stratospheric climate and chemistry. Up to now, studies of the DM were done to a major part with climate models with coupled interactive oceans. The novelty of our experiment setting was to include interactive chemistry to a GCM coupled with a deep layer ocean. We succeeded thus to include the most important natural forcing in a climate model simulation during the DM: (a) solar irradiance changes, which can be decomposed into the ultraviolet (UV), visible and infrared (IR) parts of the spectrum, (b) explosive tropical volcanic eruptions and (c) energetic particle precipitation (EPP).

Solar activity has been monitored for a long time (Wolf, 1861; Hoyt and Schatten, 1998). The influence of the Sun on time scales of up to hundreds of years can first be divided into two temporal classes; there is a regular, well established 11 yr cycle (Wolf, 1861; Schwabe, 1844) - which can vary in its intensity - and, on a longer time scale, there are grand minimum and maximum states of the solar activity.

Solar influence can be further classified in terms of where its largest effects can be observed in the Earth's atmosphere. This is strongly linked to the part of the spectrum with the largest variability. Kodera and Kuroda (2002) investigated the effects of the $11 \mathrm{yr}$ solar cycle on atmospheric dynamics, focusing on the UV part of the spectrum. Their work suggests a downward propagation of the response in the middle atmosphere caused by heating through UV absorption and ozone increase. In solar active conditions, this additional heating leads to an increasing pole-to-equator temperature gradient, influencing also the stratospheric zonal winds (Kodera and Kuroda, 2002). This process is known as the top-down mechanism (e.g. Meehl et al., 2009; Gray et al., 2010). A different aspect is to focus rather on the visible spectrum and to follow a bottom-up approach (Meehl et al., 2009): during active solar conditions, more evaporation occurs in the subtropics. This in turn leads to an increase in the precipitation amount, which accelerates the Hadley and Walker cells (Labitzke et al., 2002), finally leading to ENSO-like (El Niño-Southern Oscillation) anomalies and influencing stratospheric circulation. Using reconstructions of the solar irradiance like the ones from Lean et al. (1995), these two processes have been studied extensively in recent years using models of different complexity (see Gray et al., 2010 and references therein).

The fact that volcanoes can influence global climate has already been recognized in Franklin (1784) and Milham (1924). While Franklin (1784) mainly focused on the effect on the troposphere, which, after the Lakagigar (Laki) eruption, was polluted by a large amount of particles, partly leading to a constant haze, Milham (1924) focused on the Tambora eruption and the uncommon weather pattern following the eruption. In the twentieth century, partly because of four major volcanic eruptions (Agung in 1963, Fuego in 1974, El Chichón in 1982, Pinatubo in 1991), more intense scientific research was done. This research focusing especially on the radiative effects of stratospheric aerosols (see Hansen et al., 1992; Stenchikov et al., 1998; Robock, 2000, and references therein). The plume of powerful volcanic eruptions reaches the stratosphere (Halmer et al., 2002). There, $\mathrm{SO}_{2}$ is transformed, through a number of chemical reactions, to sulfate aerosols. Aerosols at lower stratospheric altitudes (Whitten et al., 1980) are mostly spherical (Tratt and Menzies, 1994) and reflect part of the incoming solar short-wave radiation back to space. On the other hand, sulfate aerosol absorb thermal radiation. The aerosol particles also provide a medium for heterogeneous reactions facilitating the removal of reactive nitrogen oxides and the activation of halogen radicals. Thus, volcanic aerosols are important for both radiative and chemical processes in the atmosphere.

Reconstructions of the volcanic forcing (Gao et al., 2008) have been used to model past and present-day influences of volcanic events on the global climate. Generally, following observations and modelling studies, while the lower stratosphere is heated by absorption of infrared radiation by the aerosols, the troposphere and the surface usually experience a significant cooling after major volcanic eruptions (Dutton and Christy, 1992; Minnis et al., 1993; Stenchikov et al., 1998; Arfeuille, 2012). The interaction with chemistry is more complex due to the effects of enhanced halogen loading in modern times (Tie and Brasseur, 1995). In a clean preindustrial atmosphere, a significant globally averaged increase of total column ozone can be expected within one to three years after a volcanic eruption, whereas at the equator, ozone column depth is decreasing slightly (Arfeuille, 2012). In the halogen-contaminated atmosphere of today, global ozone concentration drops significantly after a volcanic eruption. The resulting heating leads to major changes in the atmospheric dynamics and large-scale oscillation patterns like El Niño, Arctic Oscillation (AO) or North Atlantic Oscillation (NAO) (Robock, 2000; Stenchikov et al., 2002; Yoshimori et al., 2005; Wagner and Zorita, 2005; Christiansen, 2007; Fischer et al., 2007; Spangehl et al., 2010). 
The influence of EPP on climate is - compared to the other two aforementioned factors - a rather new subject to science and has been investigated increasingly often during the last twenty years. Its effect is still not well known and is a quite controversial issue in the climate change discussion (Marsh and Svensmark, 2000; Laut, 2003; Lockwood and Fröhlich, 2007; Erlykin et al., 2013). This disagreement is also a reason why EPP have not been included in important climate model simulation campaigns in support of WMO (World Meteorological Organization) and IPCC (Intergovernmental Panel on Climate Change) assessments (WMO, 2011; Forster et al., 2007). The EPP can be divided into three main categories: galactic cosmic rays (GCRs), solar protons, and high- and low-energy electrons (HEE, LEE). All of these types of EPP can ionize neutral molecules in the Earth's atmosphere.

The GCRs are highly energetic, charged particles. They originate from supernova explosions in our galaxy and their flux and energy spectrum at the entry of the heliosphere is very stable over millennial timescales, only being modulated by the solar activity, which is shielding the Earth from them via magnetospheric deflection (see e.g. Scherer et al., 2004). The observed GCR flux variability thus follows the cycles of the solar magnetic activity. GCRs are highly energetic particles, often relativistic with energies reaching several GeVs (Bazilevskaya et al., 2008), being capable in influencing our atmosphere in important ways: GCRs dissipate their energy mainly by ionization processes. Following a Bragg-peak (Bragg and Kleeman, 1905), the maximal ionization rate by GCR is reached at altitudes between $15 \mathrm{~km}$ and $20 \mathrm{~km}$ (Usoskin et al., 2010). The ionization is largest in the polar regions (poleward of $\pm 60^{\circ}$ ) where the geomagnetic field has the weakest shielding effect (lowest cut-off rigidity).

Solar proton events (SPEs) emerge from coronal mass ejections of the Sun, which occur very irregularly and are rarely directed towards the Earth. Hence, SPEs are very sporadic and hardly predictable. The solar wind plasma usually reach the Earth's atmosphere within 1-2 days after the ejection (Kahler, 1992). The charged particles are directed towards the poles, where they follow the lines of the geomagnetic field into the atmosphere. Only in extreme cases - when their energies reach $500 \mathrm{MeV}$ or more - they can propagate down to the stratosphere (Jackman et al., 2008). As a result of the magnetic shielding, the effect of SPEs is strongly latitude dependent with an equatorward minimum of $\pm 20^{\circ}$ and a poleward maximum of $\pm 60^{\circ}$.

LEEs and HEEs originate from the interaction of the Earth's magnetospheric plasmasheet with the solar wind (Brasseur and Solomon, 2005). Solar plasma is kept trapped in the magnetosphere of the Earth and can be accelerated during periods of higher solar wind speeds. The accelerated electrons then rapidly travel along the magnetic field lines to the poles and partly penetrate the uppermost layers of the atmosphere (Bazilevskaya et al., 2008). The best evidence for their existence are the aurorae, formed by the excitation of nitrogen and oxygen atoms.
Ionization of oxygen and nitrogen lead to $\mathrm{NO}_{\mathrm{x}}$ and $\mathrm{HO}_{\mathrm{x}}$ production.

In the stratosphere, while $\mathrm{HO}_{\mathrm{x}}$ has a short life time (in the range of minutes to hours) and thus affects atmospheric chemistry only locally, reactive nitrogen $\left(\mathrm{NO}_{\mathrm{y}}\right)$ and its representative species nitric acid and chlorine nitrate have lifetimes comparable to, or even longer than, the characteristic times for vertical and horizontal mixing (which occur, for instance, via the Brewer-Dobson circulation (BDC)). In the stratosphere, $\mathrm{NO}_{\mathrm{x}}$ and $\mathrm{HO}_{\mathrm{x}}$ interact with ozone in a significant way, as was found by analysing important ionization events (Callis et al., 1998; Funke et al., 2011). Changes in ozone concentration inside the polar vortex modify the poleto-equator temperature gradient and thus can have a significant influence on circulation and weather patterns (Gray et al., 2010). Different modelling studies demonstrated the influence of EPP not only on chemistry (Jackman et al., 2008; Baumgaertner et al., 2009; Egorova et al., 2011; Calisto et al., 2011; Rozanov et al., 2012b) but also on dynamics (Baumgaertner et al., 2009; Calisto et al., 2011; Rozanov et al., 2012b).

Climate during the DM minimum has already been simulated with general circulation models (GCM) in a number of studies (Bauer et al., 2003; Wagner and Zorita, 2005; Ammann et al., 2007; Spangehl et al., 2007; Arfeuille, 2012). While Bauer et al. (2003) only used a simplified model, Wagner and Zorita (2005) and Spangehl et al. (2007) exploited a coupled atmosphere-ocean GCM (AO-GCM). Arfeuille (2012) used the chemistry-climate model (CCM) SOCOL to simulate the effects of the Tambora volcanic eruption in 1815 on the climate and found a strong geopotential height gradient anomaly (around $250 \mathrm{gpm}$ ) between $55^{\circ} \mathrm{N}$ and $75^{\circ} \mathrm{N}$ at $50 \mathrm{hPa}$ in the first winter after the eruption (NovemberApril), as well as a net radiative forcing anomaly reaching $-8 \mathrm{~W} \mathrm{~m}^{-2}\left(60^{\circ} \mathrm{S}-60^{\circ} \mathrm{N}\right)$ during the first five months following the eruption. Thus, volcanic influences and solar Grand Minima are generally accepted as main drivers for global climate cooling. Wagner and Zorita (2005) also investigated the contribution of the slightly increasing GHG concentrations during the DM and did not find any significant impact.

In this paper, we investigate the effect of different natural factors on global stratospheric climate during the DM with a fully interactive atmosphere-ocean-chemistry climate model (AO-CCM). To the best of our knowledge, no coupled AO-CCM with EPP parameterization has yet been used for an in-depth analysis of the climate and chemistry state during the DM so far. This is also a reason why a comparison and a validation of our model simulation is nearly impossible to carry out: although investigations of the influence of EPP on the modern climate have been done (Calisto et al., 2011; Rozanov et al., 2012b), the far higher chlorofluorocarbon (CFC) content nowadays makes it difficult to compare the effect on the chemistry and especially on ozone. Concerning the effects of volcanic eruptions, e.g. the work of Arfeuille (2012) can give some hints how another model (the 
former model version SOCOLv2 without interactive ocean) has simulated the Tambora eruption. Yet, exact numbers in ozone disturbance are sparse and thus lso here, a validation of our results is difficult.

A description of the model framework is done in Sect. 2. In Sect. 3, we describe the chemical and dynamical changes in the stratosphere. In the last chapter, we discuss and summarize the findings of this work.

\section{Description of the model and experimental set-up}

\subsection{AO-CCM SOCOL3-MPIOM}

The AO-CCM SOCOL3-MPIOM emerges from the coupling of the CCM SOCOL3 (Stenke et al., 2013) and the ocean model MPIOM (Marsland et al., 2003) with the OASIS3 coupler (Valcke, 2013). SOCOL3 consists of the chemistry module MEZON (Model for Evaluation of oZONe trends, Rozanov et al., 1999; Egorova et al., 2003; Schraner et al., 2008) which is coupled to the GCM MA-ECHAM5 (Roeckner et al., 2003). Atmospheric temperature fields are passed to MEZON, which computes the tendencies of 41 gas species, taking into account 200 gas-phase, 16 heterogeneous, and 35 photolytical reactions. Once computed, the chemical tendencies are handed back to ECHAM5, which then takes care of the transport of species. The simulations were run in T31 spectral resolution, which is equivalent to a grid spacing of around $3.75^{\circ}$. The vertical spacing is irregular, as the model uses hybrid sigma pressure coordinates on 39 levels from $1000 \mathrm{hPa}$ up to $0.01 \mathrm{hPa}(80 \mathrm{~km})$. The chemistry scheme is only called every two hours - simultaneously with the radiative scheme - in order to be computationally efficient.

Due to this relatively coarse vertical resolution, the QuasiBiennial-Oscillation (QBO) is not reproduced autonomously by the GCM. To reproduce the QBO, the equatorial zonal wind field is nudged to reconstructed data in the same manner as described in Giorgetta (1996).

The original ECHAM5 radiation code does not properly treat solar spectral irradiation forcing (Forster et al., 2011): therefore, extra-heating correction factors (Zhu, 1994) for the Lyman-alpha line, the Schumann-Runge, and the Hartley and Huggins bands as well as for the Herzberg continuum were implemented. The radiation code was also modified in such a way that ECHAM5 reads in spectrally resolved solar irradiance in the six ECHAM5 short-wave bands with varying distribution instead of the standard fixed distribution of the varying total solar irradiance into the six bands.

Parameterization of the different EPPs was done identically to Rozanov et al. (2012b) and ref. therein, with the only difference being that the code has been modified for use in SOCOLv3. Highly energetic electrons (HEE) were not included in the model. To include the magnetic dependency of the ionization by EPP, a temporal, locally changing dipole magnetic field was implemented in the model using geomagnetic proxy data as input.

\subsection{Boundary conditions}

The model is forced by several boundary conditions described in the following section.

The GHG concentrations for the 1780 to 1840 period of carbon dioxide, methane and nitrous oxide are based on the Palaeoclimate Modelling Intercomparison Project Phase III (PMIP3) protocol (Etheridge et al., 1996, 1998; MacFarlingMeure, 2004; Ferretti et al., 2005; MacFarling-Meure et al., 2006). Halogen-containing species were kept constant to preindustrial levels.

All forcings influenced by the activity level of the Sun were based on the solar modulation potential reconstructions produced from ${ }^{10} \mathrm{Be}$ records from ice cores: for the spectral solar irradiance forcing, we use the reconstruction of Shapiro et al. (2011). In Fig. 1, the radiative forcing data is plotted for the six bands of ECHAM5 radiation code. The main difference between this reconstruction and the former ones like Lean et al. (1995) or Bard et al. (2000) is the amplitude of the variability. For example, the difference between the maximum and the minimum total solar irradiance (TSI) value during the DM is roughly $6 \mathrm{Wm}^{-2}$, whereas in, e.g. Lean et al. (1995), the drop was only by $2 \mathrm{~W} \mathrm{~m}^{-2}$. For the photolysis rates, look-up tables are used, which have been generated from the spectral solar irradiance (SSI) of Shapiro et al. (2011) are used.

Several different datasets were used for the energetic particles. For the parameterization of $\mathrm{NO}_{\mathrm{x}}$ influx, Baumgaertner et al. (2009) used the $A_{\mathrm{p}}$ index which can be reconstructed as far as back as the year 1932. The $A_{\mathrm{p}}$ index can be correlated with the $A_{\mathrm{a}}$ index, which has a longer time frame but is only based on two stations. It is available from 1868 to present. Based on sunspot numbers, the $A_{\mathrm{a}}$ and $A_{\mathrm{p}}$ indexes can be reconstructed via correlation until the year 1600 . SPEs were prescribed from an existing SPE dataset (provided by Charles Jackman and covering the period 1963-2008, see Jackman et al., 2009). SPEs are very short-lived (in the order of days); thus such events cannot be reconstructed from proxies like ${ }^{10} \mathrm{Be}$, which are usually used. Shea et al. (2006) presented a solution to reconstruct big events, like the Carrington event, from nitrates deposited in ice cores. This method, however, is very controversial (Wolff et al., 2008; Schrijver et al., 2012). In our work, SPEs are randomized for the years before 1963 by using a return-period based analysis of the last $45 \mathrm{yr}$, and weighted with the $A_{\mathrm{p}}$ index. Cosmic rays are based on the solar modulation potential $(\Phi)$, which has been reconstructed by Steinhilber et al. (2008). The dataset compares well with the neutron monitor measurements which are available for since the year 1950. $\Phi$ is an index which describes the solar modulation of the cosmic ray flux, which can be converted into pressure-latitude ionization rates using look-up tables from Usoskin et al. (2010). Palaeo-magnetic datasets 

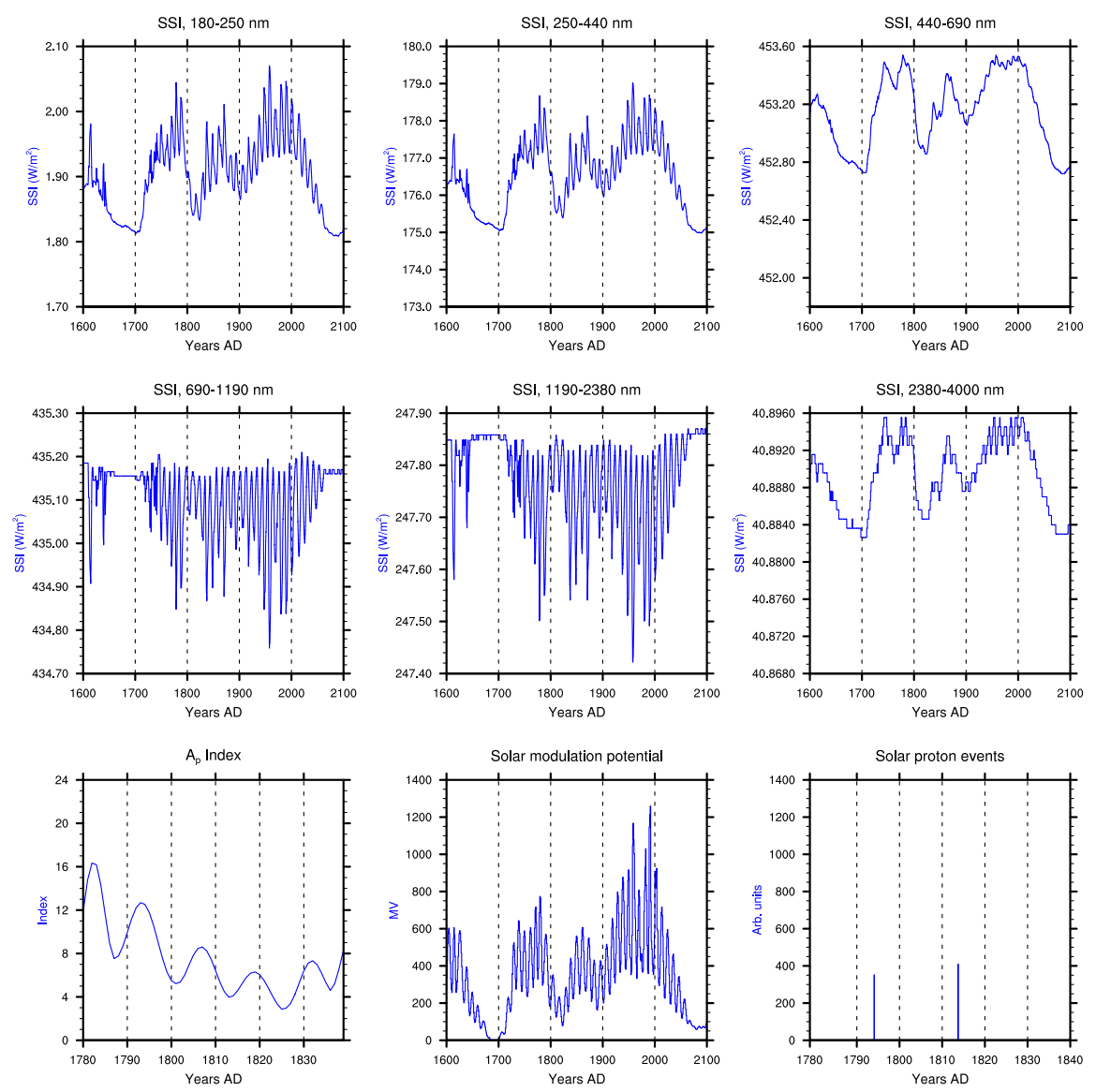

Fig. 1. Spectral solar irradiance (SSI) adapted from Shapiro et al. (2011) and $A_{\mathrm{p}}$-index, solar modulation potential and SPE during the DM. From left to right, top to bottom: hard UV (185-250 nm, band 1), soft UV (250-440 nm, band 2), visible (440-690 nm, band 3), IRA (690-1190 nm, band 4), IR-B (1190-2380 nm, band 5), IR-C (2380-4000 nm, band 6), $A_{\mathrm{p}}$-index, Solar modulation potential ( $\left.\Phi\right)$, and SPEs.

(C. Finlay, personal communication, 2010) are applied to the model in order to take into account the geomagnetic dependency of the ionization.

Stratospheric aerosol properties are prescribed according to the approach applied by Arfeuille et al. (2013a) who used the Atmospheric and Environmental Research Inc. (AER) model (Weisenstein et al., 1997) constrained with ice-corebased estimates of sulphate aerosol mass (Gao et al., 2008, 2012). From those simulations, zonally averaged aerosol optical properties (spectrally resolved) and surface area density forcing data for SOCOL3-MPIOM were extracted. The most important volcanoes during the DM period where two weak eruptions ( 1 and $3 \mathrm{Mt} \mathrm{SO}_{2}$ ) in 1794 and 1796 with unknown locations (probably extratropical), a strong unknown tropical eruption of $27 \mathrm{Mt} \mathrm{SO}_{2}$ in 1809 , the $55 \mathrm{Mt} \mathrm{SO}_{2}$ Tambora eruption in 1815 and two eruptions ( $8.5 \mathrm{Mt}$ and $20 \mathrm{Mt} \mathrm{SO}_{2}$ ) - the Babuyan Claro in 1831 and the Cosigüina in 1835.

Uncertainties in historical long-term volcanic aerosol datasets can be large, and pose more challenges for representation than does the well-observed Pinatubo 1991 eruption.
Indeed, the lack of atmospheric observations leads to uncertainties arising from ice-core measurements and calibrations, and from the implementations of volcanic datasets, which generally involve further assumptions (e.g. altitude and size distributions of the aerosols). The volcanic forcing applied here is based on an aerosol model for the calculation of these variables, and the strengths of this method for the depiction of the aerosol latitude/altitude/size distributions for eruptions in the pre-satellite period are described in Arfeuille et al. (2013a). As many CCMs, also SOCOL tends to overestimate the stratospheric warming following the Pinatubo eruption (Eyring et al., 2006; Lanzante, 2007), and the AER-based SOCOL simulation of the Pinatubo eruption (Arfeuille et al., 2013b) suggests that AER-SOCOL might also overestimate the stratospheric warming due to the eruptions in the Dalton minimum. While this issue is one of the current uncertainties for the representation of volcanic impacts in the presatellite period, it can be noted that in the important tropicaltropopause region, SOCOL forced by AER leads to a good representation of temperature after the Pinatubo eruption, 
even in better agreement with observations than many GCMs forced by satellite-based aerosol datasets.

Tropospheric aerosol properties were constructed by scaling the existing CAM3.5 simulations with a bulk aerosol model driven by CCSM3 (CMIP4) sea-surface temperatures and the 1850-2000 CMIP5 emissions (S. Bauer, personal communication, 2011). For data before the year 1850, the applied scaling is a function of the world population except for $10 \%$ of the presumed 1990 biomass burning aerosols which were considered natural.

The model was forced by the standard (Hagemann et al., 1999; Hagemann, 2002) land surface datasets provided with the ECHAM5 package.

Finally, equatorial zonal mean zonal winds for nudging the QBO were generated from a backward extension of the Brönnimann et al. (2007) reconstructions using an idealized QBO cycle plus a seasonal anomaly cycle.

\subsection{Experiments}

To investigate the influence of solar, volcanic and the EPP forcings, we perform a series of three-members ensemble sensitivity experiments described in Table 1 . We initialize our runs in the year 1780 from a transient simulation starting in 1388 AD. While the first ensemble member is run with unperturbed initial 1780 conditions, the two following members are initialized with an ocean field of the years 1781 and 1779, respectively. Every experiment covers $60 \mathrm{yr}$ to reach December 1840 . The analyzed period is chosen to be from 1805 to 1825 in order to reduce the noise and strengthen the signal from volcanic, solar and particle forcings. The small number of ensemble members is chosen to reduce the computational time needed for the simulations.

To address the relative roles of the UV, visible and infrared radiation, as well as the extra heating and the photolysis rates, two experiments called DM-TD (top-down) and DM-BU (bottom-up) are designed. In DM-TD, all forcing data is kept constant except (i) the first radiation band (UV) of ECHAM5 radiation code, (ii) the coefficients of extraheating parameterization, as well as (iii) the photolysis rates. Hence, all forcing comes from the stratosphere because the response of the heating rate in the second band of ECHAM5 radiation code $(240-440 \mathrm{~nm})$ to the solar variability is very small (Forster et al., 2011). The opposite experiment, DM$\mathrm{BU}$, is designed in a way that all forcing is kept constant except in bands $2-6$ of the ECHAM5 radiation code. Hence, DM-BU does not include any stratospheric heating or ozone production changes, meaning that all extra radiation is absorbed mostly in the troposphere and by the surface. In turn, the DM-VOLC runs are driven with all forcings except the volcanic forcing kept to constant 1780 conditions. The DMCTRL1780 runs are performed with perpetual 1780 conditions, whereas the DM-ALL runs are driven with all forcings in transient conditions. To address the effect of energetic particles, we carry out the DM-EPP experiment which is forced only by the parameterizations for GCR, SPE and LEE, while all other forcings are set constant or switched to background aerosol concentrations (volcanic forcing).

\subsection{Method of comparison}

In the next section we analyze $60 \mathrm{yr}$ long time series of annual zonal mean quantities constructed from the results of three $20 \mathrm{yr}$ long ensemble runs for each experiment. The statistical significances were calculated using the two-tailed Student's $t$ test using the $5 \%$ significance level, and comparing all $60 \mathrm{yr}$ long time series for each experiment. All figures illustrate the relative or absolute deviation of the results of the experiment runs relative to the control run (DM-CTRL1780). On all plots, the yellow line indicates the height of the dynamical WMO tropopause. The nonlinearities are computed in the following way: the differences of DM-TD, DM-BU, DM-VOLC and DM-EPP relative to DMCTRL1780 are computed and added. This field is then compared to the difference field between DM-ALL and DMCTRL1780. A positive value in the nonlinearity plot would mean that the stacked relative differences are greater than the combined differences from DM-ALL. Nonlinearities are only discussed when the sum of the contributions and the combined modelled effect are significantly different.

If not noted differently, the upper left figure of every panel illustrates the overall effect of all factors (DM-ALL), followed by the effects of UV solar irradiance (DM-TD), volcanic aerosols (DM-VOLC) and energetic particle precipitation (DM-EPP). As a reduction of the visible and infrared radiation in the DM-BU experiment has small effects on the stratospheric chemistry, these results are not shown in the chemical section.

\section{Results}

\subsection{Atmospheric chemistry}

In this section, we focus on four species: ozone, water vapour, $\mathrm{HO}_{\mathrm{x}}$ and $\mathrm{NO}_{\mathrm{x}}$, as they show the most pronounced response to the considered factors.

\subsubsection{Ozone}

Figure 2a shows the relative effect of DM-ALL including all factors - namely the reduction of solar radiation, volcanic eruptions and EPP - with respect to the control simulation (DM-CTRL1780). Substantial ozone depletion is found almost everywhere, reaching its maximum $(-8 \%)$ in the upper tropical mesosphere and middle stratosphere over the high latitudes. However, the opposite response is simulated in the polar upper mesosphere and tropical upper troposphere/lower stratosphere (UT/LS) regions where the ozone mixing ratio increases by up to $15 \%$. 
Table 1. Experiments for DM sensitivity runs: CONST values are monthly mean values from 1780. BCKGRD means that only background aerosol emissions were enabled and volcanic eruptions were turned off. TRANS means transient forcing.

\begin{tabular}{lcccccc}
\hline Name & UV & VIS & Volcanic & EPP & Photolysis & Extra Heating \\
\hline DM-CTRL1780 & CONST & CONST & BCKGRD & CONST & CONST & CONST \\
DM-ALL & TRANS & TRANS & TRANS & TRANS & TRANS & TRANS \\
DM-TD & TRANS & CONST & BCKGRD & CONST & TRANS & TRANS \\
DM-BU & CONST & TRANS & BCKGRD & CONST & CONST & CONST \\
DM-VOLC & CONST & CONST & TRANS & CONST & CONST & CONST \\
DM-EPP & CONST & CONST & BCKGRD & TRANS & CONST & CONST \\
\hline
\end{tabular}

Figure $2 b$ shows that mainly the effects of the solar UV reduction in DM-TD are responsible for the ozone loss at ozone-layer height and for the gain of ozone in the polar upper mesosphere. These ozone changes in the atmosphere can be explained mostly by three factors:

1. the decrease in solar UV irradiance which reduces the ozone production via oxygen photolysis in the stratosphere and $\mathrm{NO}_{2}$ photolysis in the troposphere,

2. the increase of $\mathrm{NO}_{\mathrm{x}}$ (see Fig. 5, Sect. 3.1.3), which facilitates the intensification of the $\mathrm{NO}_{\mathrm{x}}$ cycle of ozone oxidation (Reactions R1-R3),

$$
\begin{aligned}
& \mathrm{NO}+\mathrm{O}_{3} \rightarrow \mathrm{NO}_{2}+\mathrm{O}_{2}, \\
& \mathrm{NO}_{2}+\mathrm{O} \rightarrow \mathrm{NO}+\mathrm{O}_{2},
\end{aligned}
$$

Net:

$$
\mathrm{O}_{3}+\mathrm{O} \rightarrow 2 \mathrm{O}_{2}
$$

3. the slight compensation of the above-mentioned ozone depletion processes due to the stratospheric cooling caused by reduced solar UV and ozone mixing ratio, slowing down the ozone destruction cycles (see Sect. 3.2.1).

At the poles in lower mesospheric height $(60-80 \mathrm{~km})$ a surplus of ozone by up to $20 \%$ is explained by the fact that at these heights, the UV radiation acts like a sink rather than a source of ozone. Thus, with less UV radiation, near the mesopause, ozone destruction is suppressed.

The surplus of ozone at the tropical tropopause can be explained by volcanic effects with the DM-VOLC experiment (see Fig. 2c). The main reason for the ozone increase in the tropical UT/LS after volcanic eruptions is the transformation of $\mathrm{NO}_{\mathrm{x}}$ to $\mathrm{N}_{2} \mathrm{O}_{5}$ and the subsequent hydrolysis of $\mathrm{N}_{2} \mathrm{O}_{5}$ to $\mathrm{HNO}_{3}$ via heterogeneous reactions on/in the sulfuric acid particles, formed in the stratosphere from the products of the volcanic eruptions. In the present day atmosphere, ozone depletion was observed after major volcanic eruptions and attributed to catalytic reactions involving reactive halogens. However, a potentially significant background of natural chlorine and bromine existed. The effect of this back-
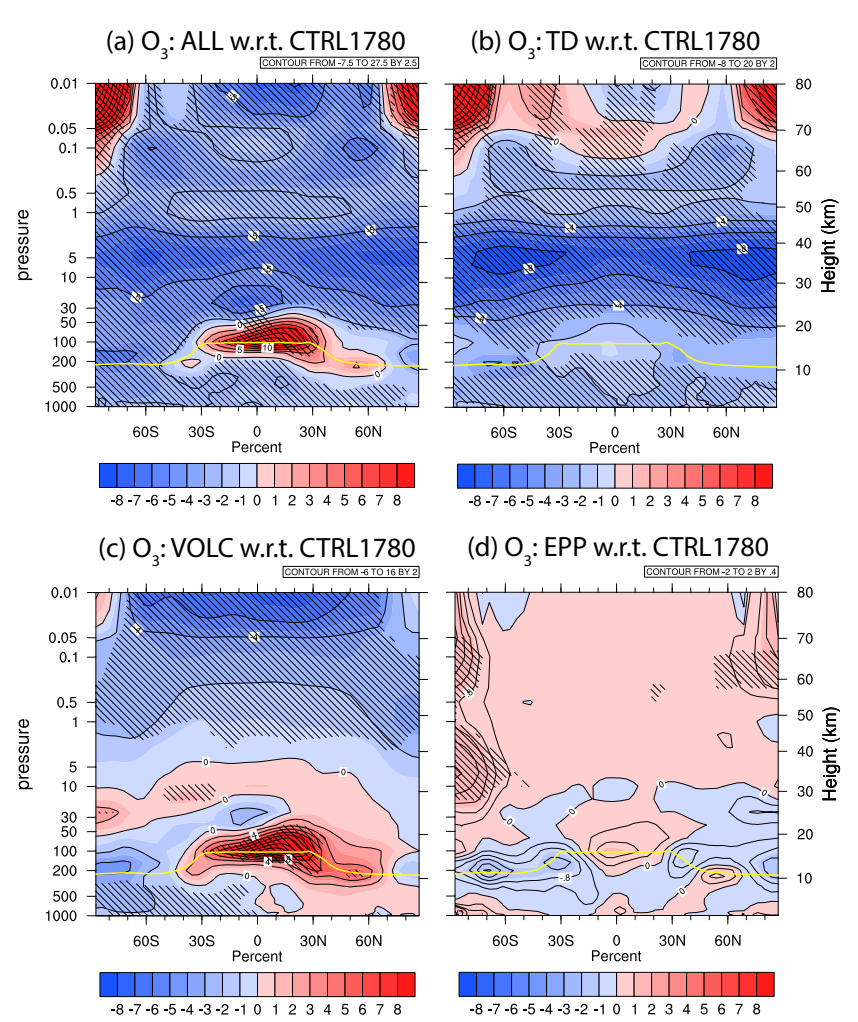

Fig. 2. Relative differences of yearly mean ozone of the DM-ALL, DM-TD, DM-VOLC and DM-EPP experiments with relation to the DM-CTRL1780 forcing run. Hatched areas are significantly different on a Student's $t$ test with $\alpha=5 \%$. The yellow line illustrates the height of the WMO tropopause.

ground, to cause ozone depletion, would have been dominated by nitrogen deactivation on sulphate aerosol. Therefore, the heterogeneous conversion of $\mathrm{HO}_{\mathrm{x}}$ and $\mathrm{NO}_{\mathrm{x}}$ to relatively passive reservoir species leads to an ozone increase of to up to $16 \%$. The decrease of ozone in the mesosphere is related to the strong increase of the $\mathrm{HO}_{\mathrm{x}}$ species at that height (see Sect. 3.1.2), leading to an acceleration of the ozone depletion cycle.

Energetic particles can influence the ozone concentration, as shown in Rozanov et al. (2012b). Although our $\mathrm{NO}_{\mathrm{x}}$ field looks very similar to the one from the cited work (see 
Sect. 3.1.3), the ozone response to EPP in the polar mesosphere is much weaker in our simulations. The main reason for this finding is that background temperatures in the involved regions are different in SOCOLv3 from SOCOLv2. Though, the reaction of nitrogen with oxygen is highly temperature dependent (Funke et al., 2011). Thus, only a minor part of the signal seen in Fig. 2a can be attributed to EPP: the annual mean ozone anomaly shows an ozone decrease of up to $2 \%$ in the southern extratropics, which is due to the ionization of nitrogen by GCRs. The change, however, is only significant on a $10 \%$ level. Over the poles, in the lower mesosphere, a significant increase of ozone of up to $2 \%$ is simulated due to the lower ionization rates of both SPEs and LEEs, leading to less $\mathrm{NO}_{\mathrm{x}}$ (see later). Seasonal variations are visible. The biggest effect is modelled in austral spring (SON, see Fig. S1 in the Supplement), where significant losses of ozone at UT/LS level of up to $4 \%$ are found in the southern polar latitudes.

The temporal evolution of ozone at $70 \mathrm{hPa}$ (Fig. S2 in the Supplement) and at $1 \mathrm{hPa}$ (Fig. S3 in the Supplement), averaged between $20^{\circ} \mathrm{N}-20^{\circ} \mathrm{S}$, are illustrated in the Supplement. They show that while the volcanic events dominate in the overall signal at the tropical-tropopause height, it is the solar signal which dominates overall at $1 \mathrm{hPa}$ height (blue curve of DM-TD experiment inducing a negative anomaly visible in the pink DM-ALL curve). Other forcing factors which are not of importance at $70 \mathrm{hPa}$ height have not been plotted.

\subsection{2 $\mathrm{HO}_{\mathrm{x}}$ and water vapour}

In Figs. 3a and 4a the differences in water vapour and $\mathrm{HO}_{\mathrm{x}}$ in DM-ALL and water vapour and $\mathrm{HO}_{\mathrm{x}}$ in DM-CTRL1780 are illustrated. While water vapour concentration increases dramatically above the tropopause, $\mathrm{HO}_{\mathrm{x}}$ is experiencing an increase in tropical UT/LS and a decrease in the mesosphere and middle tropical stratosphere.

The results of the DM-TD experiment illustrated in Fig. 3b and Fig. $4 \mathrm{~b}$ help to attribute the $\mathrm{H}_{2} \mathrm{O}$ increase and $\mathrm{HO}_{\mathrm{x}}$ loss in the mesosphere to the introduced decrease of solar UV irradiance. A strong (by up to $25 \%$ ) $\mathrm{HO}_{\mathrm{x}}$ decrease in the mesosphere, coinciding with a pronounced increase of $\mathrm{H}_{2} \mathrm{O}$, is driven by less intensive water vapour photolysis in the Lyman-alpha line and Schumann-Runge bands. When looking at the highest levels of the model atmosphere, one recognizes that $\mathrm{HO}_{\mathrm{x}}$ decreases less in the lower mesosphere than at stratopause levels (see Fig. 4b). This can be explained by looking at the increase of the water vapour content in Fig. 3b. As water vapour is more prominent during periods of decreasing UV radiation above $60 \mathrm{~km}$ due to the decrease in photodissociation, production of $\mathrm{OH}$ via reaction with $\mathrm{O}(1 \mathrm{D})$ is more likely. Moreover, a cooling of the upper troposphere/lower stratosphere (UT/LS) of $0.1 \mathrm{~K}$ decreases the stratospheric water content by $2 \%$. Hence, as the mean decrease of temperature at UT/LS height (shown in the dynamics section) in our DM-TD run is of around $0.2 \mathrm{~K}$, a de-
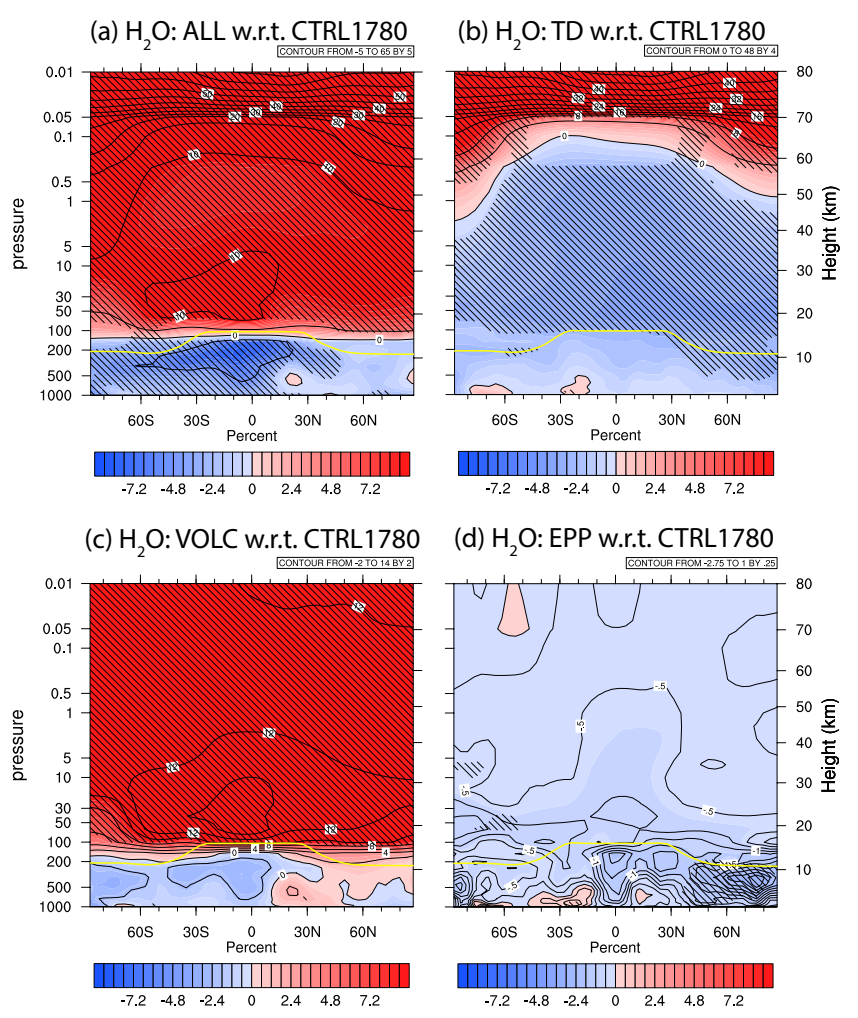

Fig. 3. Relative differences of yearly averaged water vapour of the DM-ALL, DM-TD, DM-VOLC and DM-EPP experiments with relation to the DM-CTRL1780 forcing run. Hatched areas are significantly different on a Student's $t$ test with $\alpha=5 \%$. The yellow line illustrates the height of the WMO tropopause.

crease of roughly $4 \%$ of the stratospheric water content is to be expected - and modelled. This drop is the reason for the observed decrease in $\mathrm{HO}_{\mathrm{x}}$ (of $4 \%$ on average) below $65 \mathrm{~km}$ down to the tropopause.

To explain the strong increase of water vapour above the tropopause, a look at the results of the DM-VOLC experiment (see Fig. 3c) is needed. Due to a warming signal (which will be shown in Section "Temperature"), a strong (of up to $14 \%$ ) increase in the stratospheric water content is modelled even when the results are averaged over a $20 \mathrm{yr}$ long period (see Robock, 2000). It is interesting to note that in the two years after Tambora, simulated water vapour contents rise by up to $60 \%$ at the tropical tropopause. Such a strong increase in water vapour content leads to an acceleration of the reactions

$$
\begin{aligned}
& \mathrm{H}_{2} \mathrm{O}+\mathrm{O}\left({ }^{1} \mathrm{D}\right) \rightarrow \mathrm{OH}+\mathrm{OH}, \\
& \mathrm{H}_{2} \mathrm{O}+h v \rightarrow \mathrm{H}+\mathrm{OH},
\end{aligned}
$$

in the lower mesosphere and stratosphere. Hence, an increase in $\mathrm{HO}_{\mathrm{x}}$ throughout the whole stratosphere and mesosphere (see Fig. 4c) is observed, with peak increases over the equatorial tropopause. The increase in $\mathrm{HO}_{\mathrm{x}}$ leads to a speed-up in the oxidation of long-lived species like methane or $\mathrm{CO}$. 

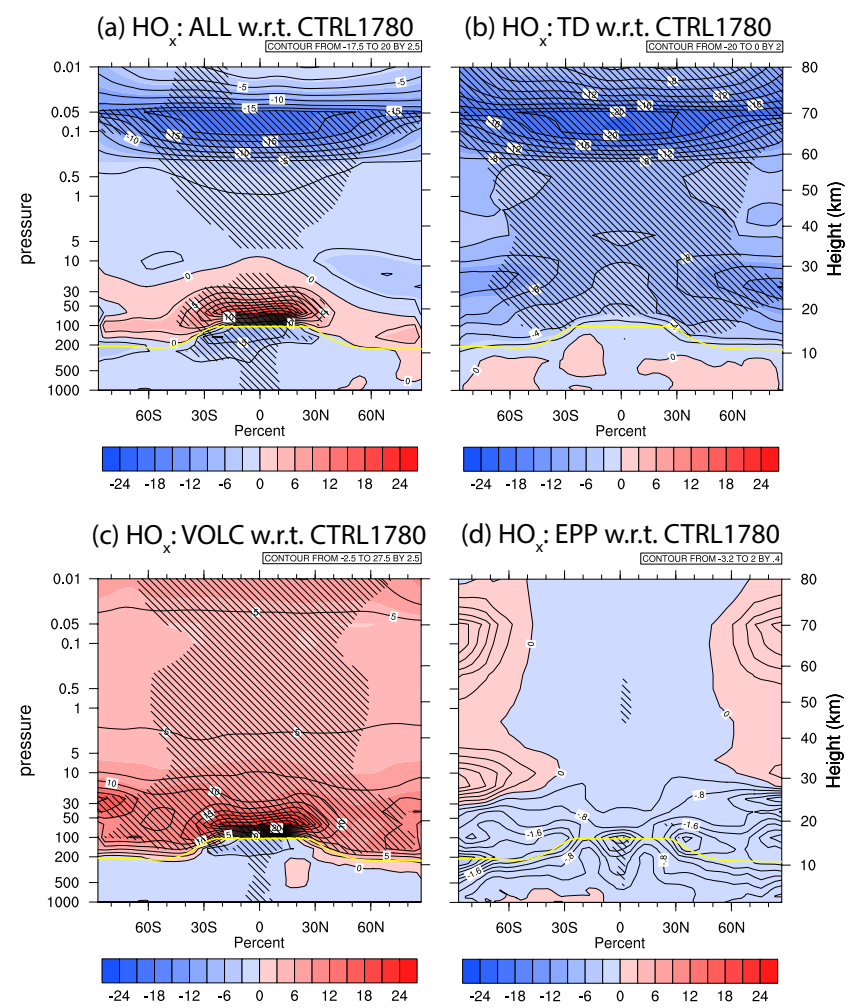

Fig. 4. Relative differences of yearly averaged $\mathrm{HO}_{\mathrm{x}}$ of the DMALL, DM-TD, DM-VOLC and DM-EPP experiments with relation to the DM-CTRL1780 forcing run. Hatched areas are significantly different on a Student's $t$ test with $\alpha=5 \%$. The yellow line illustrates the height of the WMO tropopause.

In a clean and unpolluted atmosphere, a surplus of nitrogen oxides automatically leads to the drop in $\mathrm{HO}_{\mathrm{x}}$ concentrations. In Fig. $4 d$, the additional $\mathrm{NO}_{\mathrm{x}}$ produced (see next subsection) from the GCRs decreases the amount of $\mathrm{HO}_{\mathrm{x}}$ slightly. These changes are marginally significant on a $5 \%$ level but highly significant on a $10 \%$ level in the tropical regions of the largest ionization rates (around $100 \mathrm{hPa}$ ). A decrease of $\mathrm{HO}_{\mathrm{x}}$ of up to $3 \%$ - and, during the absolute minimum of the DM, even of up to $8 \%$ - is simulated by our model. This decrease is supported by the slight additional decrease of 0.5 to $1 \%$ in the stratospheric water vapour content (Fig. 3d).

\subsection{3 $\mathrm{NO}_{\mathrm{x}}$}

In the DM-ALL experiment, the $\mathrm{NO}_{\mathrm{x}}$ mixing ratio dramatically decreases in the polar mesosphere by up to $70 \%$ and - with much smaller magnitude - also decreases in the tropical middle stratosphere. In the tropical upper troposphere and in the stratosphere, an increase in $\mathrm{NO}_{\mathrm{x}}$ is found (see Fig. 5a), which reaches its maximum in the upper tropical stratosphere/lower mesosphere. The latter can be explained by the smaller solar UV forcing in the DM-TD exper-
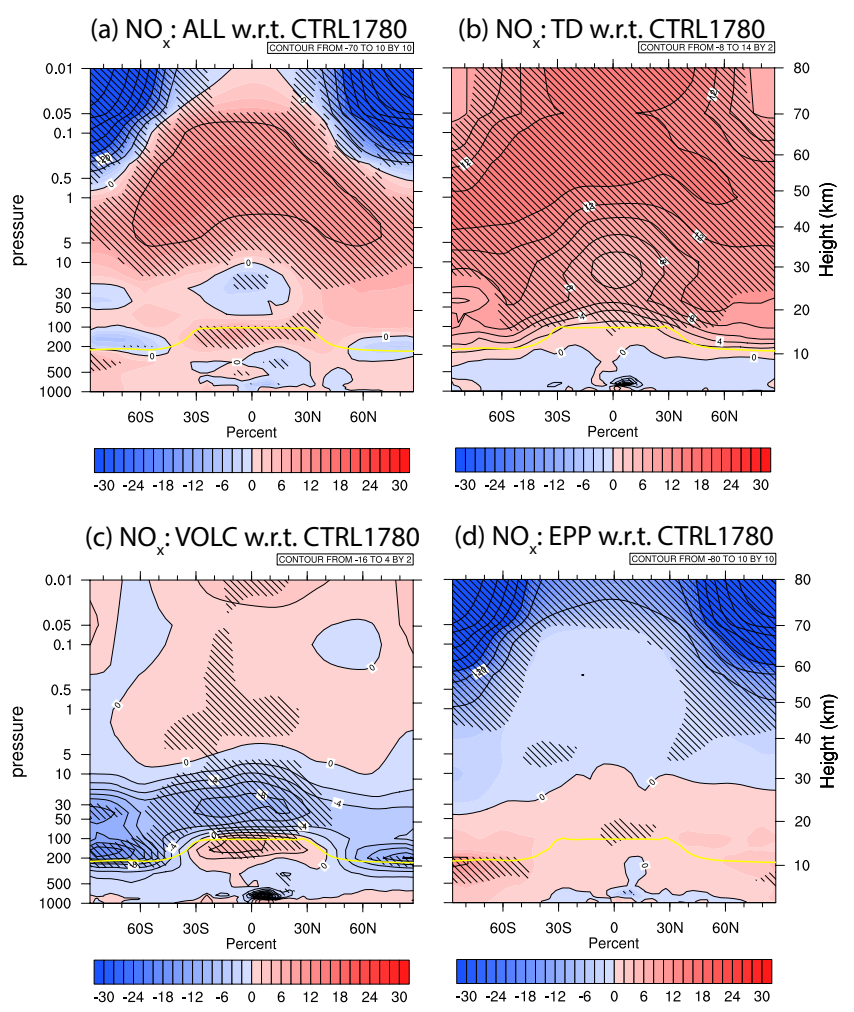

Fig. 5. Relative differences of $\mathrm{NO}_{\mathrm{x}}$ of the DM-ALL, DM-TD, DM-VOLC and DM-EPP experiments with relation to the DMCTRL1780 forcing run. Hatched areas are significantly different on a Student's $t$ test with $\alpha=5 \%$. The yellow line illustrates the height of the WMO tropopause.

iment (see Fig. 5b). The reduction in the solar UV irradiance leads to a pronounced decrease of the photolysis rates for all species, including nitrogen oxide (NO). The NO absorption bands overlap with the oxygen Schumann-Runge bands $(170-200 \mathrm{~nm})$ and the introduced decline of the solar irradiance in this interval is one of the most pronounced (Shapiro et al., 2011). The NO photolysis ( $\mathrm{NO}+h v \rightarrow \mathrm{N}+\mathrm{O}$ ) plays a crucial role in the $\mathrm{NO}_{\mathrm{y}}$ budget, providing pure loss of $\mathrm{NO}_{\mathrm{y}}$ via the subsequent cannibalistic reaction $\left(\mathrm{N}+\mathrm{NO} \rightarrow \mathrm{N}_{2}+\mathrm{O}\right)$ which explain the overall $\mathrm{NO}_{\mathrm{x}}$ increase in the DM-TD experiment.

The dipole structure in the tropical UT/LS is explained by the influence of the volcanic eruptions. The volcanic sulfate aerosols provide a media for a number of fast heterogeneous reactions. For the clean stratosphere during the DM, the most important reaction was the $\mathrm{N}_{2} \mathrm{O}_{5}$ hydrolysis, which facilitates the conversion of active nitrogen oxides to rather passive nitric acid. This effect is shown in Fig. 5c which illustrates the results of the DM-VOLC experiment. A significant $\mathrm{NO}_{\mathrm{x}}$ decrease over the $\mathrm{DM}$ period is observed in this experiment above the tropopause over the tropics and at high latitudes where the aerosol abundance is at a maximum. The causes for a small $\mathrm{NO}_{\mathrm{x}}$ increase in the tropical 
upper troposphere are not clear; probably it is related to the ozone increase in this area which leads to an enhanced $\mathrm{NO}_{\mathrm{x}}$ production via $\mathrm{N}_{2} \mathrm{O}+\mathrm{O}\left({ }^{1} \mathrm{D}\right) \rightarrow \mathrm{NO}+\mathrm{NO}$.

As expected, most of the changes in $\mathrm{NO}_{\mathrm{x}}$ seen in Fig. 5a is dominated by energetic particles (see Fig. 5d). The $\mathrm{NO}_{\mathrm{x}}$ influx, parameterized as the function of $A_{\mathrm{p}}$ index, weakened in intensity during the $\mathrm{DM}$, leading to a $\mathrm{NO}_{\mathrm{x}}$ decrease by up to $80 \%$. Particles with higher energies - to a large part GCRs, whose flux was higher during the DM - penetrate deeper into the atmosphere. At tropopause levels, GCRs produce up to $6 \%$ more $\mathrm{NO}_{\mathrm{x}}$ at the poles and up to $2 \%$ more $\mathrm{NO}_{\mathrm{x}}$ at the equator. While an increase in $\mathrm{NO}_{\mathrm{x}}$ concentrations above $50 \mathrm{~km}$ has only a small effect on the ozone layer, $\mathrm{NO}_{\mathrm{x}}$ production at lower altitudes may lead to an acceleration of the destruction of ozone via Reactions (R1)-(R3). This insight could be of high importance for the possible future decrease in solar activity in the current century (see Anet et al., 2013). The $\mathrm{NO}_{\mathrm{x}}$ anomalies compare well to those found in Rozanov et al. (2012b). The reason why the positive change in $\mathrm{NO}_{\mathrm{x}}$ is not reflected in Fig. 5a is that conversion to $\mathrm{NO}_{\mathrm{y}}$ occurs due to the additional amount of stratospheric aerosols from the volcanic eruptions. In DM-ALL, a strong decrease in $\mathrm{NO}_{\mathrm{y}}$ is seen over the whole tropopause region.

The $\mathrm{NO}_{\mathrm{x}}$ field is a good example to show the non-linear behaviour of atmospheric chemistry (see Fig. 6a). Superimposing all relative differences of all experiments, the mesospheric polar regions from the stacked DM-BU, DM-TD, DM-VOLC and DM-EPP result in significant differences of up to $15 \%$ more $\mathrm{NO}_{\mathrm{x}}$ compared to DM-ALL. The $\mathrm{NO}_{\mathrm{x}}$ field in the lower stratosphere over the northern extratropics also shows also a significant positive anomaly of $2-4 \%$ more $\mathrm{NO}_{\mathrm{x}}$. The analysis of the $\mathrm{NO}_{\mathrm{y}}$ field in Fig. $6 \mathrm{~b}$ shows an even more pronounced anomaly when superimposing all differences of all contributions together and comparing this result to the DM-ALL field: values of up to $25 \%$ more $\mathrm{NO}_{\mathrm{y}}$ in the mesospheric polar atmosphere and in the northern polar mid-stratospheric region are reached. These differences stem partly from the NO photolysis, which was kept to constant 1780 values during the DM-EPP run. As well, the additional cooling during the DM-VOLC run resulted in $\mathrm{NO}_{\mathrm{x}}$ deactivation over the poles, which could not happen during the DM-TD run.

The temporal evolution of $\mathrm{NO}_{\mathrm{x}}$ at $70 \mathrm{hPa}$ (Fig. S4 in the Supplement) and at $1 \mathrm{hPa}$ (Fig. S5 in the Supplement), averaged between $20^{\circ} \mathrm{N}-20^{\circ} \mathrm{S}$, are illustrated in the Supplement. The main signal at $70 \mathrm{hPa}$ height again - as for ozone - is dominated by the volcanoes. The remaining forcings are relatively unimportant at this height and have not been plotted. At $1 \mathrm{hPa}$ height, it is the solar signal which is dominant, although spikes do appear in volcanic periods. The latter anomalies, however, go back to normal values 1-2 yr after the volcanic eruptions. A negative $\mathrm{NO}_{\mathrm{x}}$ anomaly due to EPP is not yet visible at this altitude. (a) $\mathrm{NO}_{x}$ : Non-linearities

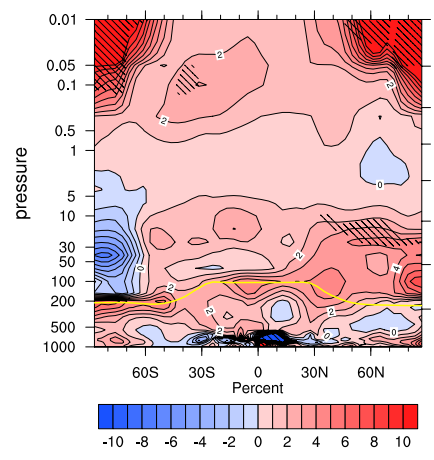

(b) $\mathrm{NO}_{\mathrm{y}}$ : Non-linearities

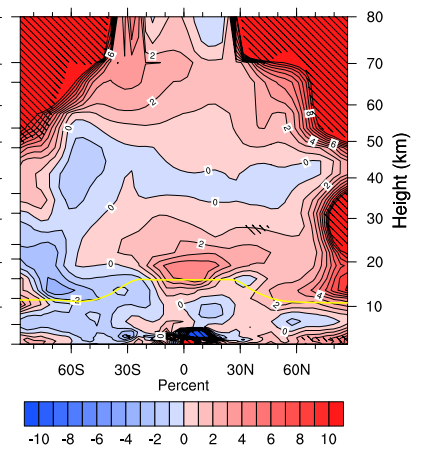

Fig. 6. Differences between the DM-ALL vs. DM-CTRL1780 field and between the (DM-TD + DM-BU + DM-VOLC + DM-EPP) vs. DM-CTRL1780 field. Positive values show a positive anomaly of the stacked differences over the DM-ALL difference field. Hatched areas are significantly different on a Student's $t$ test with $\alpha=10 \%$. The yellow line illustrates the height of the WMO tropopause.

\subsection{Stratospheric dynamics}

In this section we present the changes of the stratospheric temperature and winds during the DM and identify the contribution of all considered factors.

\subsubsection{Temperature}

As it is shown in Fig. 7a, during the DM, the model simulates cooling in the entire atmosphere except the lower tropical stratosphere. The cooling gradually increases with altitude from $1 \mathrm{~K}$ in the middle stratosphere around $25 \mathrm{~km}$, up to $8 \mathrm{~K}$ near the mesopause. A slight enhancement of the cooling is also visible in the lower polar stratosphere. Weaker cooling of up to $0.6 \mathrm{~K}$ occurs below $100 \mathrm{hPa}$ maximizing in the tropical upper troposphere.

Figure $7 \mathrm{~b}$ shows the temperature changes due to implied decrease of visible and infrared solar irradiance (experiment DM-BU) and demonstrates that this factor is producing a weak cooling in the troposphere and in the upper stratosphere. The tropospheric cooling is explained by less energy income to the surface, while the cooling in the stratosphere is most likely caused by the decrease in available solar radiation for the ozone absorption in the Chappuis band. The temperature changes due to solar UV irradiance (experiment DM-TD) are illustrated in Fig. 7c which shows that this factor plays the dominant role in the cooling of the atmosphere above $25 \mathrm{~km}$. The results shown in Fig. $7 \mathrm{~d}$ demonstrate that the influence of volcanic eruptions has a more complicated spatial pattern. The volcanic aerosols produce a strong warming of up to $2 \mathrm{~K}$ at around $20 \mathrm{~km}$ in the tropical and subtropical region. The volcanic aerosol is able to absorb infrared solar and terrestrial radiation (e.g. Stenchikov et al., 1998). The obtained strong warming in the lower tropical stratosphere means that the increased absorption of the terrestrial 
radiation by volcanic aerosols dominates over the absorption of the solar radiation, which should lead to a cooling due to the introduced decrease of the solar activity during the DM. As discussed in the introduction, this warming effect may be overestimated by our AO-CCM in the lower stratosphere, while at the tropopause there are good chances that our model - forced by AER data - reproduces an accurate warming right after the eruption. The warming in the UT/LS region explains the strong increase of water vapour in the stratosphere which was illustrated in Sect. 3.1.2. The cooling in the upper part of the model domain is explained by the blocking of the outgoing terrestrial radiation by the aerosol layer, leading to a decrease of the incoming energy in these layers. The dipole-like structure of the temperature changes over the polar regions would hint on the intensification of the polar night jets: this suspicion is confirmed when analysing seasonal means, which show a strong statistical significant acceleration on the $5 \%$ level of the north polar night jet and a significant increase on the $10 \%$ level of the southern polar night jet (see Fig. S6 in the Supplement). The blocking of the solar visible and infrared radiation by volcanic aerosols leads to a cooling in the troposphere.

Due to dilution and gravitational settling as well as washout processes, the volcanic aerosols concentration decreases over time. This has an implication on the temperature anomalies: we find that lower stratospheric temperatures revert to climatology, which is in agreement with Robock (2000).

The annual mean temperature changes from EPP are small and not statistically significant. Seasonal means, however, show significant differences: the austral winter seasonal means show a dipole pattern over the South Pole (Fig. 9a). A significant drop in temperatures (by as much as $0.7 \mathrm{~K}$ ) between $100 \mathrm{hPa}$ and $5 \mathrm{hPa}$ is modelled in winter, deepening in spring to a cooling of up to $1 \mathrm{~K}$. At the same time, a heating of approximately the same amplitude in a height between $1 \mathrm{hPa}$ and $0.05 \mathrm{hPa}$ is modelled. We explain the pattern over the southern pole by a strengthening of the polar vortex during austral winter (see next subsection) as well as a significant positive ozone anomaly of up to $3 \%$ at $5 \mathrm{hPa}$ (Fig. 2d). Ozone at these heights act as a radiative coolant. The positive temperature anomaly at mesosphere heights is due to a faster descent of air masses (BDC), leading to a increase in diabatic heating. No significant major changes in temperature can be observed during the boreal winter season.

The analyzed nonlinearities in temperatures are only significant in the troposphere and hence not shown here.

The temporal evolution of the temperatures at $70 \mathrm{hPa}$ (Fig. S7 in the Supplement) and at $1 \mathrm{hPa}$ (Fig. S8 in the Supplement), averaged between $20^{\circ} \mathrm{N}-20^{\circ} \mathrm{S}$, are illustrated in the Supplement. The main anomalies at $70 \mathrm{hPa}$ height dominating over the analyzed period are triggered by volcanic eruptions ( $+24 \mathrm{~K}$ in 1815). Other effects can be neglected. At $1 \mathrm{hPa}$ height, it is the solar signal which is dominant (blue line, DM-TD). But - as for $\mathrm{NO}_{\mathrm{x}}$ - during the volcanic peri-
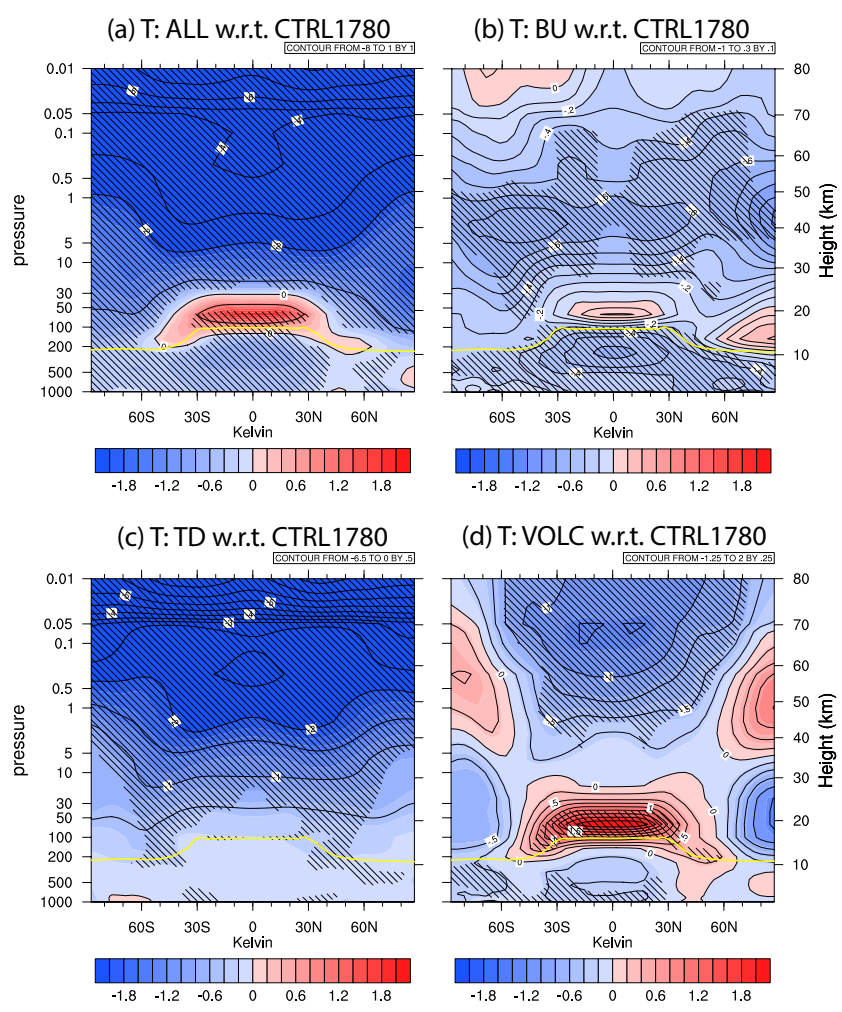

Fig. 7. Absolute differences in temperatures of the DM-ALL, DMBU, DM-TD and DM-VOLC experiments with relation to the DMCTRL1780 forcing run. Hatched areas are significantly different on a Student's $t$ test with $\alpha=5 \%$. The yellow line illustrates the WMO tropopause height.

ods, slight, short-lived ( $1 \mathrm{yr}$ ) negative temperature anomalies (negative peaks of 1-2 K) are modelled. EPP or BU radiation do not influence temperatures in such a way that it would be visible on the graphs at stratopause height.

\subsubsection{Wind and general circulation}

The combined effect of all considered factors shown in Fig. 8a consists of a strong, although only partly significant, acceleration of the zonal winds in the subtropical stratosphere from 20 to $60 \mathrm{~km}$ and in the tropical stratosphere at around $50 \mathrm{~km}$ height. By contrast, a significant deceleration of the tropical jets and a decrease of the mesospheric extratropical zonal winds are found.

Because the introduced decrease of solar activity (DM-TD and DM-BU) does not have any wider significant influence on the annual mean zonal wind and only minor upper stratospheric influence at the southern polar region in austral winter time, the majority of the changes are attributed to the influence of the volcanic eruptions.

The model result shows a strong and significant deceleration of the zonal winds from the subtropical middle troposphere down to the surface of up to $0.8 \mathrm{~m} \mathrm{~s}^{-1}$. The 
(a) U: ALL w.r.t. CTRL1780

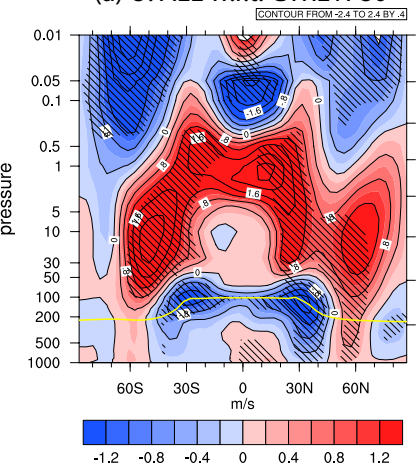

(b) U: VOLC w.r.t. CTRL1780

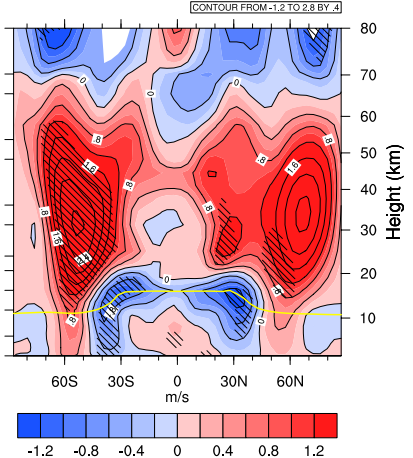

Fig. 8. Absolute differences in mean zonal wind of the DMALL and the DM-VOLC experiments with relation to the DMCTRL1780 forcing run. Hatched areas are significantly different on a Student's $t$ test with $\alpha=5 \%$. The yellow line illustrates the WMO tropopause height.

down-ward propagation of the signal is observed in both hemispheres. This effect comes from the strong, extended warming of the entire tropical lower stratosphere by volcanic aerosols (see Fig. 8d), leading to a smaller temperature gradient from the equator to the extratropics. This weakens the subtropical jets. By contrast, a significant strengthening of the polar jets up to $2.8 \mathrm{~m} \mathrm{~s}^{-1}$ is coming from the increased temperature gradient between the tropical tropopause and the polar tropopause $(\Delta T=3.2 \mathrm{~K})$. Moreover, in Fig. 10, a strong acceleration in vertical residual circulation (positive numbers are upwards) is observed after the 1809 and 1815 volcanic eruptions. Thus, the BDC is accelerated right after major volcanic eruptions. We explain this result by the finding that immediately after the volcanic eruption, cooling in the upper troposphere occurs. This favours the dissipation of gravity waves through the tropopause, leading to an additional gravity wave drag in the lower stratosphere, and hence an acceleration of the BDC. Following the heating of the lower stratosphere by the volcanic aerosols, the vertical residual circulation drops due to strengthening of the temperature gradient at the tropopause.

The DM-EPP experiment indicates positive - however, not significant - changes in annual zonal mean winds of up to $0.8 \mathrm{~m} \mathrm{~s}^{-1}$ at the stratospheric southern polar extratropics. This anomaly becomes highly significant in the austral winter seasonal mean (Fig. 9b) and reaches values of up to $1.2 \mathrm{~m} \mathrm{~s}^{-1}$. The origin of this finding is the increase of adiabatic heating by descending air masses of the BDC in austral winter. The residual vertical circulation (not shown) shows a significant increase in downward motion of the air masses by up to $0.8 \mathrm{~mm} \mathrm{~s}^{-1}$. This in turn forms a positive temperature anomaly, leading to an increase in the pole-toequator gradient at $60 \mathrm{~km}$ of height. As a consequence, the zonal wind increases. During boreal winter, a similar but less strong and non-significant pattern is found.
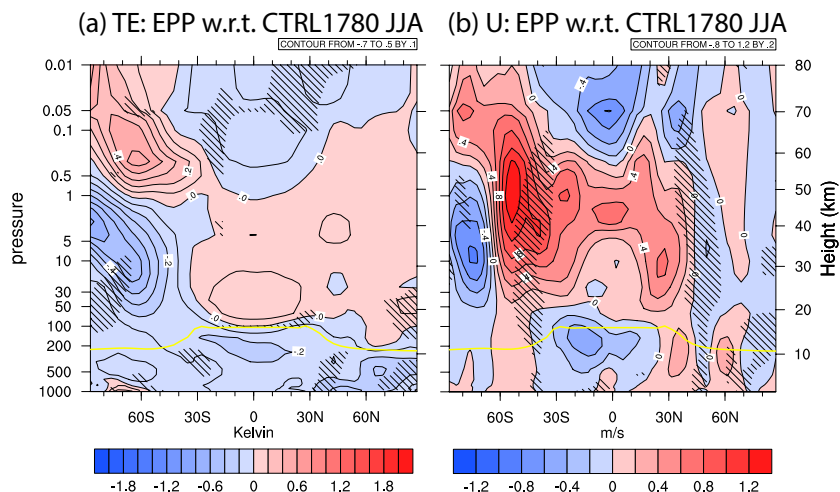

Fig. 9. Absolute JJA seasonal differences in temperature (left) and mean zonal wind (right) of the DM-EPP experiments with relation to the DM-CTRL1780 forcing run. Hatched areas are significantly different on a Student's $t$ test with $\alpha=5 \%$. The yellow line illustrates the WMO tropopause height.

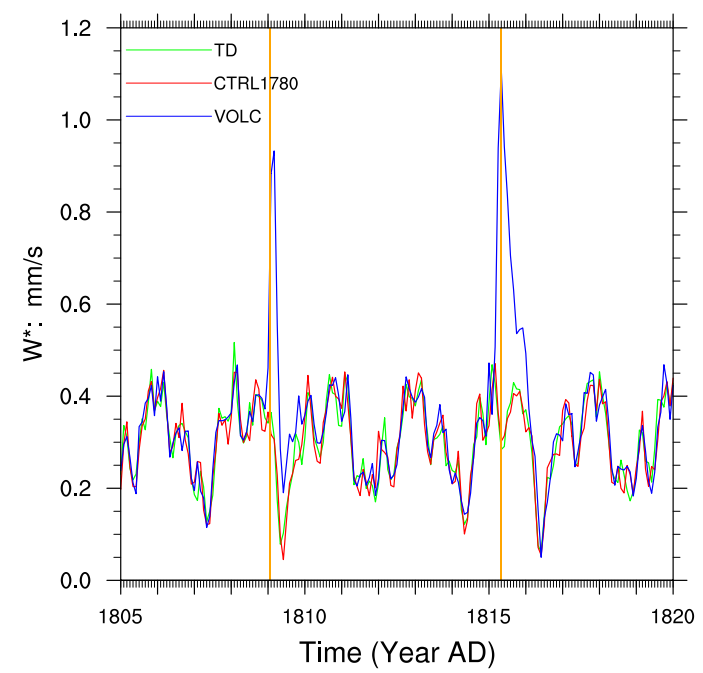

Fig. 10. Residual vertical velocity (calculation as in Andrews et al. (1987), Eqs. 3.5.1 to 3.5.3) from 1805 to 1820 for the DMCTRL1780, DM-VOLC and DM-TD simulations at $30 \mathrm{hPa}$ height averaged from $20^{\circ} \mathrm{N} / 20^{\circ} \mathrm{S}$. The two major volcanic eruptions in 1809 (unknown) and 1815 (Tambora) are marked with two vertical orange lines. The data are averages of the three ensemble members and are not smoothed.

Nonlinearities in the zonal wind field are especially well visible at the southern extratropical stratopause, where a positive bias of up to $2 \mathrm{~ms}^{-1}$ is found (not shown). We assign this anomaly to the complex interaction between the DMVOLC temperature gradient changes and the overall DM-TD negative temperature anomaly, which could have led to significant higher temperature gradient changes especially at the stratopause. 


\section{Conclusions}

We present in this paper, we present a modeling study of the different forcings which could have led to the dynamical and chemical changes in the stratosphere during the DM from 1805 to $1825 \mathrm{AD}$. The contributions, analyzed with four sensitivity experiments, include decrease in visible and near infrared radiation (DM-BU), UV radiation (DM-TD), volcanic eruptions (DM-VOLC) and energetic particles, the latter including an increase of galactic cosmic rays ionization and a decrease of solar proton events and low energetic electron precipitation (DM-EPP). A comparison of DM-TD, DM-VOLC and DM-EPP to the control run showed major significant changes. However, when comparing DM-BU to the control run, we did not succeed in identifying any noticeable changes neither in stratospheric chemistry nor in the stratospheric dynamics - except for the mid-stratospheric temperature field. This is mainly due to the drop of only $1 \%$ in the radiation band 3 from the Shapiro et al. (2011) reconstruction.

The reconstructions of the solar irradiance for past times remain highly uncertain (Judge et al., 2012; Shapiro et al., 2013; Solanki and Unruh, 2013) since no direct long-term measurements are available. We are aware of the fact that by using a strong solar forcing, the temperature, wind and chemical responses will be correspondingly strong, so that a comparison to a weaker forcing might be in place. However, in the recent work of Anet et al. (2013), we compared the ozone response using the strong forcing of Shapiro et al. (2011) - applied here - and a weaker one. Differences were not high enough to warrant the repetition of all experiments with a weaker solar forcing.

When isolating the different contributions, our simulations show the following effects on temperatures: when reducing the solar radiation in the $185-250 \mathrm{~nm}$ band and the photolysis rates, a temperature drop, reaching higher negative anomalies at the mesosphere than at the tropopause, is modelled. The anomalies reach $0.2 \mathrm{~K}$ at the tropopause and quasiuniformly drop to values down to $6 \mathrm{~K}$ at the lower mesosphere. The main reason is the lower amount of absorption of radiation by ozone. A significant cooling of up to $0.6 \mathrm{~K}$ is observed in the middle stratosphere when reducing the irradiance of the bands 2 and 3 of the solar spectrum in our model $(250-690 \mathrm{~nm})$. In the volcanic scenario, the tropical tropopause is heated by up to $2.2 \mathrm{~K}$ due to radiative absorption by the aerosols, while a significant cooling of up to $1.2 \mathrm{~K}$ is modelled around the stratopause. In the DM-EPP scenario, only a seasonal significant change in temperatures could be modelled in JJA, leading to a dipole-like structure: a cold anomaly of $0.5 \mathrm{~K}$ in the southern polar middle stratosphere and a warming of around the same amount in the southern polar lower mesosphere.

The zonal winds did not change significantly neither in the DM-BU nor the DM-TD experiment. However, a strong significant change is modelled in the subtropics and extratrop- ics in both hemispheres in the lower and upper stratosphere by up to $2.8 \mathrm{~m} \mathrm{~s}^{-1}$ when forcing the model only with volcanic aerosols. This effect is highest in the two years following an important volcanic eruption. Same as for the temperature, changes in zonal winds in the DM-EPP scenario are only significant in the JJA seasonal mean, showing a zonal wind increase of up to $1.2 \mathrm{~m} \mathrm{~s}^{-1}$ in the southern extratropical stratosphere, which is due to the dipole-like temperature anomalies.

The analysis of the stratospheric chemistry leads to following conclusions: ozone drops by up to $8 \%$ in the ozone layer, $\mathrm{HO}_{\mathrm{x}}$ decreases by up to $20 \%$ at the stratopause and water vapour content decreases in the low stratosphere by up to $3.6 \%$ but increases by up to $40 \%$ at the lower mesosphere in the DM-TD scenario. In the DM-VOLC scenario, ozone increases by up to $16 \%$ at the tropical tropopause but decreases by up to $6 \%$ at the stratopause, $\mathrm{HO}_{\mathrm{x}}$ increases all over by up to $25 \%$, as does the water vapour amount by up to $14 \%$. These effects are highest in the two subsequent years after a major volcanic eruption (up to $60 \%$ more water vapour in the lower stratosphere in the $2 \mathrm{yr}$ after Tambora). The DM-EPP experiment showed highly significant changes in the $\mathrm{NO}_{\mathrm{x}}$ field: while a decrease of up to $80 \%$ is modelled at the mesospheric poles, an increase of up to $4 \%$ is simulated at the polar tropopause. However, no or very low effects are modelled for ozone, $\mathrm{HO}_{\mathrm{x}}$ and water vapour.

By considering the changes in dynamics and chemistry, we conclude that only due to the complex interaction of volcanic, UV solar spectral and EPP forcing, do these contributions induce changes in the dynamics and chemistry of the stratosphere during the DM. The reduction of the visible radiation plays only a minor role in most of the fields except temperature. Thus, for future modelling studies, including an interactive chemistry with separate treatment of the different spectral bands is of great importance in order to get the climate responses on solar- and volcanic forcing as realistic as possible.

Concluding, the ozone decrease was predominantly influenced by the decrease in UV radiation in the polar mesosphere and at ozone-layer height, whereas the volcanic eruptions influenced ozone concentrations at tropical-tropopause height. EPP influenced only in a minor part the ozone concentrations in the polar mesosphere. $\mathrm{HO}_{\mathrm{x}}$ and water-vapour increase were affected primarily by volcanic eruptions in the stratosphere and by UV in the lower mesosphere. $\mathrm{NO}_{\mathrm{x}}$ fields were most notably influenced by EPP in the polar mesosphere and by UV in the upper stratosphere. Stratospheric winds were influenced to a major part from volcanic eruptions to a large degree. Temperatures were mainly influenced by volcanic eruptions and UV reduction, leading to a significant warming at the tropical tropopause and to a cooling in the remaining of the atmosphere.

With respect to a possible future grand solar minimum in the 21 st century, a drop in ozone column by up to $7 \%$ due to the reduction of the UV radiation is a very significant finding. 
In combination with a similar decrease in the ozone layer thickness due to ozone-depleting substances, this may become a possible health issue on Earth. As well, the effects of a reduction of UV, volcanic eruptions, and an increase of oxidation by GCRs should be thoroughly investigated in future research of the 21st century with an AO-CCM. The evolution of the ozone layer remains an important scientific topic, as e.g. crop yields or the health of living beings are subject to both anthropogenic and natural influences.

\section{Supplementary material related to this article is available online at http://www.atmos-chem-phys.net/13/ 10951/2013/acp-13-10951-2013-supplement.zip.}

Acknowledgements. This project is supported by the Swiss National Science Foundation under the grant CRSI122130642(FUPSOL). We express our greatest thanks for this support. Moreover, we would like to acknowledge the NCL plotting tool (NCAR/CISL/VETS, 2012), which made it possible to plot the data in a nice way. E. Rozanov, A. I. Shapiro, and W. Schmutz thank COST Action ES1005TOSCA (http://www.tosca-cost.eu) for the support and fruitful discussions. We would also like to thank the two anonymous reviewers for their detailed and helpful comments.

Edited by: P. Jöckel

\section{References}

Abreu, J., Beer, J., Steinhilber, F., Tobias, S. M., and Weiss, N. O.: For how long will the current grand maximum of solar activity persist?, Geophys. Res. Lett., 35, L20109, doi:10.1029/2008GL035442, 2008.

Abreu, J., Beer, J., and Ferriz-Mas, A.: Past and future solar activity from cosmogenic radionuclides, vol. 428, Past and future solar activity from cosmogenic radionuclides. Astronomical Society of the Pacific Conference Series: SOHO-23: understanding a peculiar solar minimum, 2010.

Ammann, C., Joos, F., Schimel, D., Otto-Bliesner, B., and Tomas, R.: Solar influence on climate during the past millennium: Results from transient simulations with the NCAR Climate System Model, P. Natl. Acad. Sci. USA, 104, 3713-3718, doi:10.1073/pnas.0605064103, 2007.

Andrews, D. G., Holton, J. R., and Leovy, C. B.: Middle atmosphere dynamics, Academic Press, Orlando, USA, 1987.

Anet, J. G., Rozanov, E. V., Muthers, S., Peter, T., Brönnimann, S., Arfeuille, F., Beer, J., Shapiro, A. I., Raible, C. C., Steinhilber, F., and Schmutz, W. K.: Impact of a potential 21st century "grand solar minimum" on surface temperatures and stratospheric ozone, Geophys. Res. Lett., 40, 4420-4425, doi:10.1002/grl.50806, 2013.

Arfeuille, F.: Impacts of large volcanic eruptions on the stratosphere and climate, (Doctoral Dissertation) ETH Zürich, doi:10.3929/ethz-a-007577656, 2012.
Arfeuille, F., Weisenstein, D., Mack, H., Rozanov, E., Peter, T., and Brönnimann, S.: Volcanic forcing for climate modeling: a new microphysics-based dataset covering years 1600-present, Clim. Past Discuss., 9, 967-1012, doi:10.5194/cpd-9-967-2013, 2013a.

Arfeuille, F., Luo, B. P., Heckendorn, P., Weisenstein, D., Sheng, J. X., Rozanov, E., Schraner, M., Brönnimann, S., Thomason, L. W., and Peter, T.: Uncertainties in modelling the stratospheric warming following Mt. Pinatubo eruption, Atmos. Chem. Phys. Discuss., 13, 4601-4635, doi:10.5194/acpd-134601-2013, 2013b.

Auchmann, R., Brönnimann, S., Breda, L., Bühler, M., Spadin, R., and Stickler, A.: Extreme climate, not extreme weather: the summer of 1816 in Geneva, Switzerland, Clim. Past, 8, 325-335, doi:10.5194/cp-8-325-2012, 2012.

Bard, E., Raisbeck, G., Yiou, F., and Jouzel, J.: Solar irradiance during the last 1200 years based on cosmogenic nuclides, Tellus, 52B, 985-992, doi:10.1034/j.1600-0889.2000.d01-7.x, 2000.

Bauer, E., Claussen, M., Brovkin, V., and Huenerbein, A.: Assessing climate forcings of the Earth system for the past millennium, Geophys. Res. Lett., 30, 1276, doi:10.1029/2002GL016639, 2003.

Baumgaertner, A. J. G., Jöckel, P., and Brühl, C.: Energetic particle precipitation in ECHAM5/MESSy1 - Part 1: Downward transport of upper atmospheric $\mathrm{NO}_{\mathrm{x}}$ produced by low energy electrons, Atmos. Chem. Phys., 9, 2729-2740, doi:10.5194/acp-92729-2009, 2009.

Bazilevskaya, G., Usoskin, I., Flückiger, E., Harrison, R., Desorgher, L., Bütikofer, R., Krainev, M., Makhmutov, V., Stozhkov, Y., Svirzhevskaya, A., Svirzhevsky, N., and Kovaltsov, G.: Cosmic Ray Induced Ion Production in the Atmosphere, in: Planetary Atmospheric Electricity, edited by Leblanc, F., Aplin, K., Yair, Y., Harrison, R., Lebreton, J., and Blanc, M., vol. 30 of Space Sciences Series of ISSI,. 149-173, Springer New York, doi:10.1007/978-0-387-87664-1_10, 2008.

Bragg, W. and Kleeman, R.: On the $\alpha$ particles of radium, and their loss of range in passing through various atoms and molecules, Philos. Mag., 10, 318-340, doi:10.1080/14786440509463378, 1905.

Brasseur, G. and Solomon, S.: Aeronomy of the Middle Atmosphere, Springer Netherlands, Dordrecht, doi:10.1007/1-40203824-0, 2005.

Brönnimann, S., Annis, J. L., Vogler, C., and Jones, P. D.: Reconstructing the quasi-biennial oscillation back to the early $1900 \mathrm{~s}$, Geophys. Res. Lett., 34, 22, doi:10.1029/2007GL031354, 2007.

Calisto, M., Usoskin, I., Rozanov, E., and Peter, T.: Influence of Galactic Cosmic Rays on atmospheric composition and dynamics, Atmos. Chem. Phys., 11, 4547-4556, doi:10.5194/acp-114547-2011, 2011.

Callis, L., Natarajan, M., Evans, D., and Lambeth, J.: Solar atmospheric coupling by electrons (SOLACE) 1. Effects of the May 12, 1997 solar event on the middle atmosphere, J. Geophys. Res., 103, 28405-28419, doi:10.1029/98JD02408, 1998.

Christiansen, B.: Volcanic Eruptions, Large-Scale Modes in the Northern Hemisphere, and the El Niño Southern Oscillation, J. Climate, 21, 910-922, doi:10.1175/2007JCLI1657.1, 2007.

Dutton, E. G. and Christy, J. R.: Solar radiative forcing at selected locations and evidence for global lower tropospheric cooling following the eruptions of El Chichón and Pinatubo, Geophys. Res. Lett., 19, 2313-2316, doi:10.1029/92GL02495, 1992. 
Egorova, T., Rozanov, E., Zubov, V., and Karol, I.: Model for Investigating Ozone Trends (MEZON), Izvestiia Akademii Nauk SSSR. Seria Fizika Atmosfery i Okeana, 39, 310-326, translated by MAIK "Nauka/Interperiodica” (Russia), 2003.

Egorova, T., Rozanov, E., Ozolin, Y., Shapiro, A. I., Calisto, M., Peter, T., and Schmutz, W.: The atmospheric effects of October 2003 solar proton event simulated with the chemistry-climate model SOCOL using complete and parameterized ion chemistry, J. Atmos. Sol-Terr. Phy., 73, 356-365, doi:10.1016/j.jastp.2010.01.009, 2011.

Erlykin, A., Sloan, T., and Wolfendale, A.: A review of the relevance of the "CLOUD" results and other recent observations to the possible effect of cosmic rays on the terrestrial climate, Meteorol. Atmos. Phys., 121, 137-142, doi:10.1007/s00703-0130260-x, 2013.

Etheridge, D., Steele, L., Langenfelds, R., Francey, R., Barnola, J., and Morgan, V.: Natural and anthropogenic changes in atmospheric $\mathrm{CO}_{2}$ over the last 1000 years from air in Antarctic ice and firn, J. Geophys. Res., 101, 4115-4128, doi:10.1029/95JD03410, 1996.

Etheridge, D. M., Steele, L. P., Francey, R. J., and Langenfelds, R. L.: Atmospheric methane between 1000 A.D. and present: Evidence of anthropogenic emissions and climatic variability, J. Geophys. Res., 103, 15979-15993, doi:10.1029/98JD00923, 1998.

Eyring, V., Butchart, N., Waugh, D. W., Akiyoshi, H., Austin, J., Bekki, S., Bodeker, G. E., Boville, B. A., Brühl, C., Chipperfield, M. P., Cordero, E., Dameris, M., Deushi, M., Fioletov, V. E., Frith, S. M., Garcia, R. R., Gettelman, A., Giorgetta, M. A., Grewe, V., Jourdain, L., Kinnison, D. E., Mancini, E., Manzini, E., Marchand, M., Marsh, D. R., Nagashima, T., Newman, P. A., Nielsen, J. E., Pawson, S., Pitari, G., Plummer, D. A., Rozanov, E., Schraner, M., Shepherd, T. G., Shibata, K., Stolarski, R. S., Struthers, H., Tian, W., and Yoshiki, M.: Assessment of temperature, trace species, and ozone in chemistry-climate model simulations of the recent past, J. Geophys. Res., 111, D22308, doi:10.1029/2006JD007327, 2006.

Ferretti, D., Miller, J., White, J., Etheridge, D., Lassey, K., Lowe, D., Meure, C., Dreier, M., Trudinger, C., Van Ommen, T., and Langenfelds, R.: Unexpected changes to the global methane budget over the past 2000 years, Science, 309, 1714-1717, doi:10.1126/science.1115193, 2005.

Fischer, E. M., Luterbacher, J., Zorita, E., Tett, S. F. B., Casty, C., and Wanner, H.: European climate response to tropical volcanic eruptions over the last half millennium, Geophys. Res. Lett., 34, L05707, doi:10.1029/2006GL027992, 2007.

Forster, P., Ramaswamy, V., Artaxo, P., Berntsen, T., Betts, R., Fahey, D., Haywood, J., Lean, J., Lowe, D., Myhre, G., Nganga, J., Prinn, R., Raga, G., Schulz, M., and Van Dorland, R.: Changes in Atmospheric Constituents and in Radiative Forcing, in: Climate Change 2007: The Physical Science Basis, Contribution of Working Group I to the Fourth Assessment Report of the Intergovernmental Panel on Climate Change, Cambridge University Press, Cambridge, United Kingdom and New York, NY, USA, 2007

Forster, P. M., Fomichev, V. I., Rozanov, E., Cagnazzo, C., Jonsson, A. I., Langematz, U., Fomin, B., Iacono, M. J., Mayer, B., Mlawer, E., Myhre, G., Portmann, R. W., Akiyoshi, H., Falaleeva, V., Gillett, N., Karpechko, A., Li, J., Lemennais,
P., Morgenstern, O., Oberländer, S., Sigmond, M., and Shibata, K.: Evaluation of radiation scheme performance within chemistry climate models, J. Geophys. Res., 116, D10302, doi:10.1029/2010JD015361, 2011.

Franklin, B.: Meteorological imagination's and conjectures, Manchester Lit. Philos. Soc., 2, 122, 1784.

Funke, B., Baumgaertner, A., Calisto, M., Egorova, T., Jackman, C. H., Kieser, J., Krivolutsky, A., López-Puertas, M., Marsh, D. R., Reddmann, T., Rozanov, E., Salmi, S.-M., Sinnhuber, M., Stiller, G. P., Verronen, P. T., Versick, S., von Clarmann, T., Vyushkova, T. Y., Wieters, N., and Wissing, J. M.: Composition changes after the "Halloween" solar proton event: the High Energy Particle Precipitation in the Atmosphere (HEPPA) model versus MIPAS data intercomparison study, Atmos. Chem. Phys., 11, 90899139, doi:10.5194/acp-11-9089-2011, 2011.

Gao, C., Robock, A., and Ammann, C.: Volcanic forcing of climate over the past 1500 years: An improved ice core-based index for climate models, J. Geophys. Res., 113, D23111, doi:10.1029/2008JD010239, 2008.

Gao, C., Robock, A., and Ammann, C.: Correction to "Volcanic forcing of climate over the past 1500 years: An improved ice core-based index for climate models", J. Geophys. Res., 117, D16112, doi:10.1029/2012JD018052, 2012.

Giorgetta, M.: Der Einfluss der quasi-zweijaehrigen Oszillation: Modellrechnungen mit ECHAM4, Ph.D. thesis, Max-PlanckInstitut für Meteorologie, Hamburg, 1996.

Gray, L. J., Beer, J., Geller, M., Haigh, J. D., Lockwood, M., Matthes, K., Cubasch, U., Fleitmann, D., Harrison, G., Hood, L., Luterbacher, J., Meehl, G. A., Shindell, D., van Geel, B., and White, W.: Solar influences on climate, Rev. Geophys., 48, RG4001, doi:10.1029/2009RG000282, 2010.

Hagemann, S.: An improved land surface parameter dataset for global and regional climate models, Max-Planck-Institut für Meteorologie, Hamburg, 2002.

Hagemann, S., Botzet, M., Dümenil, L., and Machenhauer, B.: Derivation of global GCM boundary conditions from $1 \mathrm{~km}$ land use satellite data, Max-Planck-Institut für Meteorologie, 1999.

Halmer, M., Schmincke, H.-U., and Graf, H.-F.: The annual volcanic gas input into the atmosphere, in particular into the stratosphere: a global data set for the past 100 years, J. Volcanol. Geotherm. Res., 115, 511-528, doi:10.1016/S03770273(01)00318-3, 2002.

Hansen, J., Lacis, A., Ruedy, R., and Sato, M.: Potential climate impact of Mount Pinatubo eruption, Geophys. Res. Lett., 19, 215218, doi:10.1029/91GL02788, 1992.

Hoyt, D. V. and Schatten, K. H.: Group sunspot numbers: A new solar activity reconstruction, Sol. Phys., 181, 491-512, doi:10.1023/A:1005007527816, 1998.

Ineson, S., Scaife, A. A., Knight, J. R., Manners, J. C., Dunstone, N. J., Gray, L. J., and Haigh, J. D.: Solar forcing of winter climate variability in the Northern Hemisphere, Nature, 4, 753-757, doi:10.1038/NGEO1282, 2011.

Jackman, C. H., Marsh, D. R., Vitt, F. M., Garcia, R. R., Fleming, E. L., Labow, G. J., Randall, C. E., López-Puertas, M., Funke, B., von Clarmann, T., and Stiller, G. P.: Short- and medium-term atmospheric constituent effects of very large solar proton events, Atmos. Chem. Phys., 8, 765-785, doi:10.5194/acp-8-765-2008, 2008. 
Jackman, C. H., Marsh, D. R., Vitt, F. M., Garcia, R. R., Randall, C. E., Fleming, E. L., and Frith, S. M.: Long-term middle atmospheric influence of very large solar proton events, J. Geophys. Res., 114, D11304, doi:10.1029/2008JD011415, 2009.

Judge, P. G., Lockwood, G. W., Radick, R. R., Henry, G. W., Shapiro, A. I., Schmutz, W., and Lindsey, C.: Confronting a solar irradiance reconstruction with solar and stellar data, Astron. Astrophys., 544, A88, doi:10.1051/0004-6361/201218903, 2012.

Kahler, S.: Solar flares and coronal mass ejections, Annu. Rev. Astron. Astr., 30, 113-141, doi:10.1146/annurev.aa.30.090192.000553, 1992.

Kodera, K. and Kuroda, Y.: Dynamical response to the solar cycle, J. Geophys. Res., 107, 4749-4761, doi:10.1029/2002JD002224, 2002.

Labitzke, K., Austin, J., Butchardt, N., Knight, J., Takahashi, M., Nakamoto, M., Nagashima, T., Haigh, J., and Williams, V.: The global signal of the 11-year solar cycle in the stratosphere: observations and models, J. Atmos. Sol.-Terr. Phy., 64, 203-210, doi:10.1016/S1364-6826(01)00084-0, 2002.

Lanzante, J. R.: Diagnosis of Radiosonde Vertical Temperature Trend Profiles: Comparing the Influence of Data Homogenization versus Model Forcings, J. Climate, 20, 5356, doi:10.1175/2007JCLI1827.1, 2007.

Laut, P.: Solar activity and terrestrial climate: an analysis of some purported correlations, J. Atmos. Sol.-Terr. Phys., 65, 801-812, doi:10.1016/S1364-6826(03)00041-5, 2003.

Lean, J., Beer, J., and Bradley, R.: Reconstruction of solar irradiance since 1610: Implications for climate change, Geophys. Res. Lett., 22, 3195-3198, doi:10.1029/95GL03093, 1995.

Ljungqvist, F.: A new reconstruction of temperature variability in the extra-tropical northern hemisphere during the last two millenia, Geogr. Ann. A, 92, 339-351, doi:10.1111/j.14680459.2010.00399.x, 2010.

Lockwood, M. and Fröhlich, C.: Recent oppositely directed trends in solar climate forcings and the global mean surface air temperature, Proceedings of the Royal Society A: Mathematical, Physical and Engineering Science, 463, 2447-2460, doi:10.1098/rspa.2007.1880, 2007.

Lockwood, M., Owens, M., Barnard, L., Davis, C., and Steinhilber, F.: The persistence of solar activity indicators and the descent of the Sun into Maunder Minimum conditions, Geophys. Res. Lett., 38, L22105, doi:10.1029/2011GL049811, 2011b.

Luterbacher, J., Dietrich, D., Xoplaki, E., Grosjean, M., and Wanner, H.: European Seasonal and Annual Temperature Variability, Trends, and Extremes Since 1500, Science, 303, 1499-1503, doi:10.1126/science. $1093877,2004$.

MacFarling-Meure, C.: The natural and anthropogenic variations of carbon dioxide, methane and nitrous oxide during the Holocene from ice core analysis, Ph.D. thesis, University of Melbourne, 2004.

MacFarling-Meure, C., Etheridge, D., Trudinger, C., Steele, P., Langenfelds, R., Van Ommen, T., Smith, A., and Elkins, J.: Law Dome CO2, CH4 and $\mathrm{N} 2 \mathrm{O}$ ice core records extended to 2000 years BP, Geophys. Res. Lett., 33, L14810, doi:10.1029/2006GL026152, 2006.

Marsh, N. and Svensmark, H.: Cosmic rays, clouds, and climate, Space Science Reviews, 94, 215-230, doi:10.1023/A:1026723423896, 2000.
Marsland, S., Haak, H., Jungclaus, J., Latif, M., and Roske, F.: The Max-Planck-Institute global ocean/sea ice model with orthogonal curvilinear coordinate, Ocean Model., 5, 91-27, doi:10.1016/S1463-5003(02)00015-X, 2003.

Meehl, G. A., Arblaster, J. M., Matthes, K., Sassi, F., and van Loon, H.: Amplifying the Pacific Climate System Response to a Small 11-Year Solar Cycle Forcing, Science, 325, 1114-1118, doi:10.1126/science.1172872, 2009.

Milham, W.: The year 1816 - the causes of abnormalities, Mon. Wea. Rev., 52, 563-570, doi:10.1175/15200493(1924)52<563:TYTCOA>2.0.CO;2, 1924.

Minnis, P., Harrison, E., Stowe, L., Gibson, G., Denn, F., Doelling, D., and Smith, W.: Radiative climate forcing by the Mount Pinatubo eruption, Science, 259, 1411-1415, doi:10.1126/science.259.5100.1411, 1993.

NCAR/CISL/VETS: The NCAR Command Language (Version 6.0.0) [Software], Boulder, USA, 2012.

Robock, A.: Volcanic Eruptions and Climate, Rev. Geophys., 38, 191-219, doi:10.1029/1998RG000054, 2000.

Roeckner, E., Baeuml, G., Bonaventura, L., Brokopf, R., Esch, M., Giorgetta, M., Hagemann, S., Kirchner, I., Kornblueh, L., Manzini, E., Rhodin, A., Schlese, U., Schulzweida, U., and Tompkins, A.: The atmospheric general circulation model ECHAM 5. PART I: Model description, Max-Plank-Institut für Meteorologie, Hamburg, Report No. 349, http://www.mpimet. mpg.de/fileadmin/publikationen/Reports/max_scirep_349.pdf, 2003.

Rozanov, E., Schlesinger, M. E., Zubov, V., Yang, F., and Andronova, N. G.: The UIUC three-dimensional stratospheric chemical transport model: Description and evaluation of the simulated source gases and ozone, J. Geophys. Res., 104, 755-781, doi:10.1029/1999JD900138, 1999.

Rozanov, E., Calisto, M., Egorova, T., Peter, T., and Schmutz, W.: Influence of the Precipitating Energetic Particles on Atmospheric Chemistry and Climate, Surveys in Geophysics, 33, 483-501, doi:10.1007/s10712-012-9192-0, 2012b.

Scherer, K., Fahr, H.-J., Fichtner, H., and Heber, B.: Long-Term Modulation of Cosmic Rays in the Heliosphere and its Influence at Earth, Solar Physics, 224, 305-316, doi:10.1007/s11207-0055687-x, 2004.

Schraner, M., Rozanov, E., Schnadt Poberaj, C., Kenzelmann, P., Fischer, A. M., Zubov, V., Luo, B. P., Hoyle, C. R., Egorova, T., Fueglistaler, S., Brönnimann, S., Schmutz, W., and Peter, T.: Technical Note: Chemistry-climate model SOCOL: version 2.0 with improved transport and chemistry/microphysics schemes, Atmos. Chem. Phys., 8, 5957-5974, doi:10.5194/acp-8-59572008, 2008.

Schrijver, C., Beer, J., Baltensperger, U., Cliver, E., Güdel, M., Hudson, H., McCracken, K., Osten, R., Peter, T., Soderblom, D., R., D., Usoskin, I. G., and Wolff, E. W.: Estimating the frequency of extremely energetic solar events, based on solar, stellar, lunar, and terrestrial records, J. Geophys. Res., 117, A08103, doi:10.1029/2012JA017706, 2012.

Schwabe, M.: Sonnenbeobachtungen im Jahre 1843, Von Herrn Hofrath Schwabe in Dessau, Astronomische Nachrichten, 21, 233-236, 1844.

Shapiro, A. I., Schmutz, W., Rozanov, E., Schoell, M., Haberreiter, M., Shapiro, A. V., and Nyeki, S.: A new approach to the long- 
term reconstruction of the solar irradiance leads to large historical solar forcing, Astron. Astrophys., 529, A67, 2011.

Shapiro, A. I., Schmutz, W., Cessateur, G., and Rozanov, E.: The place of the Sun among the Sun-like stars, Astron. Astrophys., 552, A114, doi:10.1051/0004-6361/201220512, 2013.

Shea, M., Smart, D., McCracken, K., Dreschhoff, G., and Spence, H.: Solar proton events for 450 years: The Carrington event in perspective, Adv. Space Res., 38, 232-238, doi:10.1016/j.asr.2005.02.100, 2006.

Solanki, S. and Unruh, Y.: Solar irradiance variability, Astronomische Nachrichten, 334, 145-150, doi:10.1002/asna.201211752, 2013.

Spangehl, T., Cubasch, U., and Langematz, U.: Änderung der NAO im Maunder Minimum und einem zukünftigen Klima in Modellsimulationen mit EGMAM, Copernicus meetings, http://meetings.copernicus.org/dach2007/download/ DACH2007_A_00360.pdf (last access: June 2013), 2007.

Spangehl, T., Cubasch, U., Raible, C., Schimanke, S., Körper, J., and Hofer, D.: Transient climate simulations from the Maunder Minimum to present day: role of the stratosphere, J. Geophys. Res., 115, D00I10, doi:10.1029/2009JD012358, 2010.

Steinhilber, F. and Beer, J.: Prediction of solar activity for the next 500 years, J. Geophys. Res., 118, 1861-1867, doi:10.1002/jgra.50210, 2013.

Steinhilber, F., Abreu, J. A., and Beer, J.: Solar modulation during the Holocene, Astrophys. Space Sci., 4, 1-6, doi:10.5194/astra4-1-2008, 2008.

Stenchikov, G., Kirchner, I., Robock, A., Graf, H., Antuna, J., Grainger, R., Lambert, A., and Thomason, L.: Radiative forcing from the 1991 Mount Pinatubo volcanic eruption, J. Geophys. Res., 103, 837-857, doi:10.1029/98JD00693, 1998.

Stenchikov, G., Robock, A., Ramaswamy, V., Schwarzkopf, M. D., Hamilton, K., and Ramachandran, S.: Arctic Oscillation response to the 1991 Mount Pinatubo eruption: Effects of volcanic aerosols and ozone depletion, J. Geophys. Res., 107, ACL 28-1ACL 28-16, doi:10.1029/2002JD002090, 2002.

Stenke, A., Schraner, M., Rozanov, E., Egorova, T., Luo, B., and Peter, T.: The SOCOL version 3.0 chemistry-climate model: description, evaluation, and implications from an advanced transport algorithm, Geosci. Model Dev., 6, 1407-1427, doi:10.5194/gmd-6-1407-2013, 2013.

Tie, X. and Brasseur, G.: The response of stratospheric ozone to volcanic eruptions: Sensitivity to atmospheric chlorine loading, Geophys. Res. Lett., 22, 3035-3038, 1995.
Tratt, D. and Menzies, R.: Evolution of the Pinatubo Volcanic Aerosol Column Above Pasadena, California Observed With a Mid-Infrared Backscatter Lidar, Tech. rep., Jet Propulsion Laboratory, California Institute of Technology, http://trs-new.jpl.nasa. gov/dspace/bitstream/2014/33312/1/94-1252.pdf, 1994.

Usoskin, I. G., Kovaltsov, G. A., and Mironova, I. A.: Cosmic ray induced ionization model CRAC:CRII: An extension to the upper atmosphere, J. Geophys. Res., 115, D10302, doi:10.1029/2009JD013142, 2010.

Valcke, S.: The OASIS3 coupler: a European climate modelling community software, Geosci. Model Dev., 6, 373-388, doi:10.5194/gmd-6-373-2013, 2013.

Wagner, S. and Zorita, E.: The influence of volcanic, solar and $\mathrm{CO}_{2}$ forcing on the temperatures in the Dalton Minimum (17901830): a model study, Clim. Dyn., 25, 205-218, 2005.

Weisenstein, D., Yue, G., Ko, M., Sze, N., Rodriguez, J., and Scott, C.: A two-dimensional model of sulfur species and aerosols, J. Geophys. Res., 102, 13019-13035, doi:10.1029/97JD00901, 1997.

Whitten, R., Toon, O., and Rurco, R.: The stratospheric sulfate aerosol layer: Processes, models, observations, and simulations, Pure Appl. Geophys., 118, 86-127, doi:10.1007/BF01586447, 1980.

WMO: Scientific assessment of ozone depletion, Global Ozone Research and Monitoring Project - Report No. 52, Tech. rep., Geneva, Switzerland, http://montreal-protocol.org/Assessment_ Panels/SAP/Scientific_Assessment_2010/index.shtml, 2011.

Wolf, R.: Abstract of his latest results, Mon. Not. R. Astron. Soc., 21, 77, 1861.

Wolff, E. W., Jones, A. E., Bauguitte, S. J.-B., and Salmon, R. A.: The interpretation of spikes and trends in concentration of nitrate in polar ice cores, based on evidence from snow and atmospheric measurements, Atmos. Chem. Phys., 8, 5627-5634, doi:10.5194/acp-8-5627-2008, 2008.

Yoshimori, M., Stocker, T., Raible, C., and Renold, M.: Externally forced and internal variability in ensemble climate simulations of the Maunder Minimum, J. Climate, 18, 4253-4270, doi:10.1175/JCLI3537.1, 2005.

Zhu, X.: An accurate and efficient radiation algorithm for middle atmosphere models, J. Atmos. Sci., 51, 3593-3614, doi:10.1175/1520-0469(1994)051<3593:AAAERA>2.0.CO;2, 1994. 